\title{
Genomics and Functional Genomics of Malignant Pleural Mesothelioma
}

\author{
Ece Cakiroglu ${ }^{1,2}$ and Serif Senturk $1,2, *$ (D) \\ 1 Izmir Biomedicine and Genome Center, Izmir 35340, Turkey; ece.cakiroglu@msfr.ibg.edu.tr \\ 2 Department of Genome Sciences and Molecular Biotechnology, Izmir International Biomedicine and \\ Genome Institute, Dokuz Eylul University, Izmir 35340, Turkey \\ * Correspondence: serif.senturk@ibg.edu.tr
}

Received: 22 July 2020; Accepted: 20 August 2020; Published: 1 September 2020

\begin{abstract}
Malignant pleural mesothelioma (MPM) is a rare, aggressive cancer of the mesothelial cells lining the pleural surface of the chest wall and lung. The etiology of MPM is strongly associated with prior exposure to asbestos fibers, and the median survival rate of the diagnosed patients is approximately one year. Despite the latest advancements in surgical techniques and systemic therapies, currently available treatment modalities of MPM fail to provide long-term survival. The increasing incidence of MPM highlights the need for finding effective treatments. Targeted therapies offer personalized treatments in many cancers. However, targeted therapy in MPM is not recommended by clinical guidelines mainly because of poor target definition. A better understanding of the molecular and cellular mechanisms and the predictors of poor clinical outcomes of MPM is required to identify novel targets and develop precise and effective treatments. Recent advances in the genomics and functional genomics fields have provided groundbreaking insights into the genomic and molecular profiles of MPM and enabled the functional characterization of the genetic alterations. This review provides a comprehensive overview of the relevant literature and highlights the potential of state-of-the-art genomics and functional genomics research to facilitate the development of novel diagnostics and therapeutic modalities in MPM.
\end{abstract}

Keywords: malignant pleural mesothelioma; genomics; functional genomics; next-generation sequencing; RNAi and CRISPR screens

\section{Introduction}

Malignant pleural mesothelioma (MPM) is the cancer of the mesothelial cells of the pleura, the protective lining of the chest cavity. Although classified as a relatively rare cancer, MPM is the most common form of all mesotheliomas and is a highly aggressive and lethal cancer with nearly 25,000 deaths worldwide in 2018 [1,2]. Besides, the most recent annual statistics indicate that $\sim 30,000$ new cases [2] and $\sim 3000$ new patients are diagnosed globally and in the United States, respectively [3]. The primary etiological factor of MPM is the past occupational and environmental exposure to the exogenous factor asbestos, which accounts for $\sim 80 \%$ of the diagnosed cases $[4,5]$. Notably, asbestos-related diseases cause nearly 93,000 deaths per year worldwide, reflecting the general health risks posed by asbestos fibers [4]. Although the use of asbestos has been regulated and restricted in Western countries, the global incidence of MPM is expected to increase over the next few decades due to the long latency period of the disease, estimated to be nearly 40 years after fiber exposure. Furthermore, the increasing use, import, and export of asbestos in many non-Western developing countries render MPM a continuing global health problem [4-6]. Exposure to the fibrous mineral erionite, radiation, and simian virus 40 are other recognized causes of MPM [5]. Additionally, rare familial forms of MPM possibly due to a genetic predisposition have been identified in several countries 
worldwide and particularly studied in the United States and Turkey, such as in the famous Cappadocia region [7-10].

There are three major histological subtypes of MPM: the epithelioid (50-70\%), sarcomatoid (10-20\%), and biphasic (20-35\%). In epithelioid MPMs, tumor cells resemble the original mesothelial cells and typically present with pleural effusions and have the most favorable survival rates. Sarcomatoid MPMs, on the other hand, exhibit spindle cell morphology similar to sarcomas, are usually present with a pleural mass, and have the worst outcomes. Finally, biphasic or mixed MPMs have both epithelioid and sarcomatoid features [11,12]. The prognosis of MPM is generally poor, with a reported median overall survival of approximately one year after diagnosis, and there is no definitive cure for the disease [12]. Despite the recent developments in medical oncology, MPM is refractory to currently available multimodal therapeutic options such as chemotherapy, radiation, and surgical resection $[13,14]$. Besides, targeted therapy is not yet available for this deadly disease, even though several molecular pathways implicated in MPM have been identified to date. Of note, these pathways include cell cycle regulation, apoptosis, growth factor pathways, and angiogenesis [15]. Unfortunately, the clinical trials targeting these molecular processes have demonstrated limited, if not completely ineffective, efficacy against MPM $[13,15]$. Further studies are therefore needed for a thorough understanding of the biological basis of MPM, especially in the context of genetic, epigenetic, and transcriptomic alterations.

Interrogation of the functional significance of aberrations in cellular processes and signaling pathways is equally critical for the identification of novel molecular drivers, key vulnerabilities, and synthetic lethal interactions. Arguably, these comprehensive molecular studies may, in turn, lead to the development of effective targeted therapy strategies. In recent years, research on genomics and functional genomics of MPM, powered by next-generation molecular technologies such as DNA and RNA sequencing, high throughput RNAi (RNA interference), and CRISPR screens, and new preclinical models have begun to provide a deeper overview of the complex landscape of molecular mechanisms that contribute to MPM pathophysiology. The purpose of this review is to summarize the recent advances and significant contributions made by the researchers in the field of MPM research, in particular the next-generation and high throughput genomics and functional genomics studies. Further, we aim to address the fundamental molecular and cellular alterations underlying the pathogenesis and progression of MPM with particular emphasis on their possible implications for diagnostics and therapeutics.

\section{Genomics of Malignant Pleural Mesothelioma}

Malignant pleural mesothelioma is a heterogeneous cancer with complex underlying molecular alterations. To date, genomics analyses have revealed genetic, epigenetic, and transcriptomic deregulations in MPM.

\subsection{Genomic Landscape of Recurrently Mutated Genes in Malignant Pleural Mesothelioma}

The constant acquisition of genetic aberrations that facilitate oncogenic transformation, cellular proliferation, and invasion is a central mechanism in the course of tumorigenesis. Over the past two decades, efforts on comprehensive genomic landscape studies have contributed substantial insights into MPM biology. Owing to the rare nature and thus limited sample size, the chromosomal alterations identified and reported in the early genetics and the genomics studies of MPM were, although quite informative, usually repeated representations of recurrent mutations. Many of these genetic lesions are loss of function aberrations spurred by point mutations and/or copy number alterations (CNA) affecting multiple regions of the genome [16-19]. Unlike other cancers that are generally rich in oncogenic gain of function alterations, genomic losses in MPM carcinogenesis are more frequent. According to older karyotype and comparative genomic hybridization (CGH) studies conducted in the 1990s, losses in chromosome regions 1p, 3p, 6q, 9p, 13q, 15q, and 22q were common in MPM [20,21]. Subsequent studies have further confirmed that, along with losses, the most frequent genetic alterations 
in these chromosome regions are inactivating mutations found in the NF2, CDKN2A, BAP1, and TP53 tumor suppressor genes, which play pivotal roles in restricting malignant transformation [16-19]. More recently, the advent of next-generation sequencing (NGS) technologies and the bioinformatics revolution fostered by large-scale genomics profiling initiatives, such as the global collaborative project The Cancer Genome Atlas (TCGA) [22], have enabled the discovery of novel genetic signatures and drastically enhanced our understanding and knowledge of MPM. As a consequence, novel mechanisms such as chromosome rearrangements, gene fusions, and splicing factor alterations have been identified as inactivation mechanisms for recurrently mutated genes [23-25].

\subsubsection{Frequent Loss of Function Alterations}

The BAP1 (BRCA1-associated protein 1) gene has been reported as one of the most frequently mutated genes in MPM, affecting more than half of the tumors [26]. In general, the functional loss of the $B A P 1$ gene, which is localized to the chromosomal region $3 \mathrm{p} 31$, a region that is frequently deleted in other cancer types as well, is caused by nonsynonymous somatic mutations, splice alterations, gene fusions, and copy number alterations $[18,27,28]$. The BAP1 gene encodes a deubiquitylating enzyme with a ubiquitin carboxy-terminal hydrolase $(\mathrm{UCH})$ domain that removes ubiquitin tags from numerous nuclear and cytoplasmic proteins, in particular histones, chromatin-associated HCF-1 (host cell factor 1); ASXL1, 2, and 3 (human homologs of Drosophila Polycomb group protein ASX); and IP3R3 (Inositol 1,4,5-Triphosphate Receptor, Type 3) [29-32]. BAP1 governs crucial cellular processes by regulating the expression of several target genes that control cell cycle progression, cellular proliferation and differentiation, $\mathrm{Ca}^{2+}$-signaling mediated apoptosis, ferroptosis, and energy metabolism [33-36]. Furthermore, BAP1 interacts with a number of nuclear proteins, such as BRCA1 (Breast Cancer Type 1) and BARD1 (BRCA1-associated RING domain protein 1), and assembles an active multiprotein complex that promotes homologous recombination and double-strand break repair, thereby maintaining genomic stability and functioning as a tumor suppressor [37]. Recently, heterozygous germline mutations eventually resulting in biallelic inactivation of the BAP1 gene have been implicated in a rare condition named "BAP1 cancer syndrome", which is characterized by the increased susceptibility to multiple cancers, primarily familial MPM, and uveal melanomas, and less frequently cutaneous melanomas, breast carcinomas, cholangiocarcinomas, sarcomas, basal cell carcinomas, renal cell carcinomas, and various types of CNS tumors [38-42]. It is of particular interest to mention here that germline mutations in DNA damage sensing and repair genes, and other tumor suppressor genes may also increase the risk of MPM development. Indeed, $10 \%$ of MPM patients are carriers of heritable mutations in these cancer susceptibility genes [43-46].

Homozygous deletions of the CDKN2A (cyclin-dependent kinase inhibitor 2A) locus, specifically 9 p21, have been demonstrated to be frequent in many primary tumor types of different origin. Similarly, $C D K N 2 A$ is one of the most frequently inactivated tumor suppressor genes in MPM, deleted in about half of the cases [17]. Although less frequent, the complete genetic loss of INK4 locus, which is typically characterized by the co-deletion of $C D K N 2 A$ and its syntenic gene $C D K N 2 B$ (cyclin-dependent kinase inhibitor 2B), is also observed in MPM [21]. The human CDKN2A gene encodes two distinct tumor suppressor proteins resulting from translation of the common second exon in alternative reading frames (ARFs), namely, alpha and beta. Specifically, the alpha transcript encodes p16INK4A, while the product of the beta transcript is p14ARF. Besides, the CDKN2B gene codes for the p15INK4B protein. p14ARF is involved in the regulation of cell cycle progression and apoptosis, mainly by antagonizing the functions of MDM2 (Mouse Double Minute 2), the E3 ubiquitin-protein ligase responsible for p53 degradation [47]). Moreover, p16INK4A and p15INK4B are highly homologous proteins that are structurally and functionally similar cyclin-dependent kinase inhibitors (CDKIs). By inhibiting CDK4/6 activity, they cause hypophosphorylation and functional activation of $\mathrm{pRb}$ (the retinoblastoma tumor suppressor protein), thereby preventing cell cycle progression and proliferation [48]. Notably, the co-deletion of $C D K N 2 A$ and $C D K N 2 B$ genes is associated with a shorter overall survival rate in 
MPM. Emerging evidence suggests that MPM patients with the loss of function of p16INK4A and p15INK4B could benefit from cell cycle targeted therapies, in particular CDK4/6 inhibitors [49-51].

The other most frequent alteration in MPM involves the inactivation of the NF2 (neurofibromatosis type 2) gene, a genetic event that was first reported in the mid-1990s and occurs in nearly half of the tumors [52]. The inactivation of the NF2 gene is associated with homozygous chromosomal loss and focal deletions of the 22q12 locus. High rates of gene fusions; splicing defects; and frameshift, missense, and nonsense mutations that result in low expression or absence of the $70 \mathrm{kDa}$ tumor suppressor protein Merlin (moesin-ezrin-radixin-like protein), the protein encoded by the NF2 gene, have also been reported [53,54]. Merlin shares a similar domain organization with, and therefore belongs to, the Ezrin, Radixin, and Moesin (ERM) protein family [55]. As a multifunctional protein, Merlin mediates tumor-suppressive mechanisms by inhibiting malignant activities of cancer cells. To that extent, several studies have revealed that Merlin inhibits cell proliferation by limiting the signal transduction activities of several molecular pathways such as EGFR (epidermal growth factor receptor), PI3K (phosphoinositide 3-kinase), mTORC1/2 (mTOR complex 1/2), Hippo (Salvador-Warts-Hippo), Rac, and Ras GTPase effector pathways [56]. Besides, Merlin plays a crucial role in coupling a variety of membrane- and cytoskeleton-associated cellular processes such as cell morphology, adhesion, motility, and migration [55]. Finally, several lines of experimental evidence indicate that the functional loss of NF2 gene in MPM often contributes to increased cell spreading and invasion through recruitment and hyperactivation of FAK (focal adhesion kinase) and c-Src (SRC proto-oncogene, non-receptor tyrosine kinase) signaling pathways $[57,58]$. Taken together, probing the clinical utility of inhibiting the cellular pathways associated with the loss of Merlin activity in MPM is worth exploring.

\subsubsection{Less Common Loss of Function Genetic Alterations}

In addition to the loss of $C D K N 2 A, N F 2$, and $B A P 1$ genes, an overwhelmingly well-known tumor suppressor TP53 (tumor protein p53) gene is also, although to a lesser extent, inactivated in MPM. Mechanisms of inactivation include recurrent copy losses and nonsynonymous coding sequence mutations [23,59-61]. Inactivation of the TP53 gene was found to correlate with a less favorable overall survival rate when compared to the wild type TP53, which would underscore that the MPMs with TP53 mutations have a more aggressive phenotype [59,62]. Importantly, Hmeljak et al. has recently identified a novel molecule subtype of MPM characterized by recurrent TP53 mutations, co-mutations of the SETDB1 gene that encodes a transcriptional repressor histone methyltransferase, and genomic near-haploidization, as well as disctinct clinical attributes such as female predominance, younger age at diagnosis, and aggressive behaviour [62]. Other less frequently but recurrent significantly mutated genes documented in MPM include LATS2 (large tumor suppressor kinase 2) and SETD2 (SET domain containing 2). The LATS2 gene aberrations, usually due to large deletions and point mutations, often co-occur with NF2 inactivation, a molecular event that appears to be MPM specific [63]. The eventual coinactivation of LATS2 and NF2 genes leads to deregulation of the Hippo pathway through enhanced cotranscriptional activity of YAP1 (Yes1 associated transcriptional regulator, also known as YAP), the downstream nuclear effector protein of the Hippo signaling pathway $[63,64]$. More recently, the SETD2 tumor suppressor gene, along with other members of the SETD family genes, has been reported to be frequently inactivated in MPM through recurrent mechanisms of gene fusions, splice alterations, and nonsynonymous mutations $[23,65]$. The SETD2 gene encodes a histone lysine methyltransferase that trimethylates Lys-36 of histone $\mathrm{H3}$, an epigenetic modification associated with active transcription [66]. However, the functional consequences of SETD2 inactivation in MPM are not known. On the other hand, studies in human renal cell carcinomas suggest that the functional loss of SETD2 gene, together with other chromatin remodelers, could lead to epigenome aberrations and pathological splicing events, as discussed in further detail below. Intriguingly, a recent work by Park et al. has found that SETD2 methylates the microtubules during mitosis and cytokinesis and the loss of this function results in mitotic spindle defects, impaired DNA repair, and genomic instability, which may explain, at least in part, the high frequency of aneuploidy observed in MPM [67]. 


\subsubsection{Gain of Function Mutations}

Recurrent somatic copy number gains are less common in MPM. To date, chromosomal gains have been reported for multiple regions of the MPM genome, including 1q, 5p, 7p, 8q, and 17q. Interestingly enough, TERT gene (telomerase reverse transcriptase) copy number gains and hotspot promoter mutations constitute the first recurrent oncogenic gain of function alterations in MPM, which are generally observed in $\sim 10-15 \%$ of all cancer types. The TERT gene encodes the catalytic subunit of the telomerase complex and the reactivation of TERT expression is a hallmark of cancer. Consistent with other cancer types, the spectrum of promoter mutations found in MPM result in augmented mRNA expression and the MPM patients with TERT promoter, TP53 and NF2 mutations have shorter overall survival $[68,69]$. Of note, the promoter mutations and copy number gains are not mutually exclusive, and the chromosomal amplifications alone do not account for transcriptional activation of the TERT gene (chr location: 5p15). Further, while mutually exclusive with BAP1 inactivation, TERT promoter mutations often co-occur with CDKN2A inactivation, which warrants the rationale for appraising the clinical competence of telomerase-inhibiting therapies, alone or in combination with CDK4/6 inhibitors $[69,70]$.

Using low-pass whole genome sequencing (LP-WGS) on a set of 21 MPM cases with matched normal samples, Hylebos et al. identified novel copy number gains in the oncogenes such as $C D 79 B$ (CD79b molecule, chr location: 17q23) and MDM4 (MDM4 regulator of p53, chr location 1q32) [65]. Supported by their oncogenic roles in other cancers, MPM-specific functional understanding of these genetic alterations can make them attractive targets for MPM therapy. In one of the most comprehensive studies of MPM genomics, Bueno et al. have recently discovered recurrent gains in RPTOR (regulatory associated protein of mTOR complex 1, chr. location: 17q25), a gene with known oncogenic functions in colorectal cancer [23]. Further studies are needed to confirm or refute a similar biological function in MPM biology. Similarly, deregulated amplification of MYC gene (MYC proto-oncogene, bHLH transcription factor, chr location: 8q24), a genetic event that can be recapitulated in asbestos-induced MPMs of wild type murine models, has been reported in a small fraction of MPM cases $(<5 \%)[71,72]$.

\subsection{Novel Malignant Pleural Mesothelioma-Associated Mutations}

High-throughput NGS technologies have revolutionized genomics studies and enabled the extensive characterization of cancer-specific somatic mutations at unprecedented resolution. Further, the arrival of these technologies has promoted the development of the public cancer genomics resources, such as the Catalogue of Somatic Mutations in Cancer (COSMIC), International Cancer Genome Consortium (ICGC), and The Cancer Genome Atlas (TCGA) [73-75]. Of these, the TCGA resource that is a collaboration between the National Cancer Institute (NCI) and National Human Genome Research Institute (NHGRI), has achieved a milestone in cataloging the clinical and genomics attributes of more than 20,000 primary cancer tissues and matched normal samples, across 33 types of cancer. This unified repository offers both controlled and open access to a comprehensive resource of genetic, epigenetic, transcriptomic, and proteomic data, enabling the scientific community to address unresolved questions and make seminal discoveries in cancer.

To further expand the knowledge on MPM biology, various research groups have conducted in silico analyses on TCGA and other open access multi-institutional MPM datasets. These efforts have identified novel genetic aberrations and confirmed the earlier findings on recurrent alterations [35-42]. The data suggest that commonly detected novel variations are related to cellular processes such as DNA repair, histone methylation, RNA metabolism, and angiogenesis. Significant molecular alterations affecting PI3K-Akt, Wnt, Hippo, mTOR, PDGF (platelet-derived growth factor), and FGF (fibroblast growth factor) signaling pathways are also described [23,25,59]. Included among the mutated genes in these pathways are APC, ARID1A, BMPR1A, CHEK2, DVL1, EPHB1, FBXW7, KDR, MAP2K1, PDGFRA, PTEN, RB1, SMARCA4, SMARCB1, HRAS, NRAS, and WRN [23,24,59,70,76,77], whose genetic alterations have also been found in lung adenocarcinomas [78-80], colorectal [81-84], and breast cancers [85]. Moreover, oncogenic mutations in ABL1, EP300, PIK3CA, PIK3C2B, PTPN11, and SETDB1 
genes [23-25,59,62], and novel gains in regions encompassing RHEB, KDM5A, AXIN2, RICTOR, TRIO, and DVL1 genes were identified [24,65]. Furthermore, TP53, PIK3CA, and KDR mutations were clinically associated with significantly reduced overall survival [59]. Looking ahead, we believe that further studies based on high-throughput dataset analyses on published work or directly on publicly available genomics datasets will continue to make seminal contributions in shedding light on MPM pathobiology. In accordance with the ease of self-assessment and reporting of the TCGA dataset, we performed genomic analysis on the cohort of 87 MPM patient samples at The cBio Cancer Genomics Portal (cBioPortal) [86,87] and summarized the findings in Table 1.

\subsection{Deregulations in Signaling Pathways, Cellular Processes, and Gene Expression}

High-throughput transcriptomic profiling of MPM has revealed frequent deregulations in genes and signaling circuits that regulate cellular processes such as cell division and proliferation, DNA replication and repair, response to mitogens and stress, survival, apoptosis, and migration $[23,88]$.

Growth factor signaling pathways contribute to MPM tumorigenesis, and they are recurrently deregulated in MPM. Mechanisms of deregulation involve sustained activation of autocrine and paracrine signaling [21]. Among others, dysregulation of receptor tyrosine kinase (RTK) signaling results in abnormal activation of the PI3K/Akt/mTOR, and MAPK pathways $[62,89,90]$. These pathways regulate critical biological processes such as transcription, translation, cell proliferation, growth, and migration that are often deregulated in MPM. Independent studies have reported a positive association between phosphorylation levels of Akt, and mTOR in more than half of the MPMs. Besides, the activation of PI3K/Akt/mTOR has been associated with the loss of PTEN expression, the negative regulator of PI3K-Akt pathway [91-93]. Furthermore, MAPK cascade has displayed increased activity of the intracellular signaling molecules in older and recent reports [62,94,95]. However, the activation status of this pathway failed to differentiate between malignant and nonmalignant cells, highlighting a complex regulation in MPM $[89,95]$. Consequently, implementing therapeutic interventions appear to be challenging with the current state of MPM knowledge and additional studies will be required to define the role of the MAPK pathway in MPM pathophysiology.

Increased activity of EGFR signaling pathway has also been reported in MPM [96-98]. However, unlike lung cancer, the mutation and expression status of EGFR correlated with better overall survival in MPM patients, which may explain why the Phase II clinical trials of Erlotinib and Gefitinib, the first generation EGFR tyrosine kinase inhibitors (EGFR-TKIs), did not yield significant responses [99,100]. Overall, available data suggest that targeting the EGFR pathway with EGFR-TKIs at this time would not be considered therapeutically relevant in MPM. 
Table 1. Genomic analysis of the TCGA malignant pleural mesothelioma (MPM) cohort using the cBioPortal Resource. N/A: data not available.

\begin{tabular}{|c|c|c|c|c|c|c|c|c|}
\hline Gene Symbol & Gene Name & $\begin{array}{c}\text { Chromosomal } \\
\text { Location }\end{array}$ & GO Annotation & Molecular Function & $\begin{array}{c}\text { Mutation } \\
\text { Frequency (\%) }\end{array}$ & $\begin{array}{c}\text { CNA } \\
\text { Frequency }(\%)\end{array}$ & CNA Type & $\begin{array}{c}\text { Fusion } \\
\text { Frequency }(\%)\end{array}$ \\
\hline NF2 & Neurofibromin 2 & $22 q 12.2$ & $\begin{array}{l}\text { Actin binding and } \\
\text { cytoskeletal protein } \\
\text { binding }\end{array}$ & $\begin{array}{l}\text { Interacts with cell-surface } \\
\text { proteins, proteins } \\
\text { involved in cytoskeletal } \\
\text { dynamics and proteins } \\
\text { involved in regulating } \\
\text { ion transport. } \\
\text { Tumor suppressor }\end{array}$ & 23.3 & 8.0 & HOMDEL & 2.3 \\
\hline BAP1 & $\begin{array}{l}\text { BRCA1 } \\
\text { Associated } \\
\text { Protein } 1\end{array}$ & $3 p 21.1$ & $\begin{array}{l}\text { Chromatin binding and } \\
\text { thiol-dependent } \\
\text { ubiquitin-specific } \\
\text { protease activity }\end{array}$ & $\begin{array}{l}\text { Binds to the breast cancer } \\
\text { type } 1 \text { susceptibility } \\
\text { protein (BRCA1) via the } \\
\text { RING finger domain of } \\
\text { the latter and acts as a } \\
\text { tumor suppressor. } \\
\text { Tumor suppressor }\end{array}$ & 20.9 & 11.5 & HOMDEL & 3.5 \\
\hline TP53 & $\begin{array}{c}\text { Tumor Protein } \\
\text { P53 }\end{array}$ & $17 \mathrm{p} 13.1$ & $\begin{array}{c}\text { DNA-binding } \\
\text { transcription factor } \\
\text { activity and protein } \\
\text { heterodimerization } \\
\text { activity }\end{array}$ & $\begin{array}{l}\text { Acts as a tumor } \\
\text { suppressor in many } \\
\text { tumor types; induces } \\
\text { growth arrest or } \\
\text { apoptosis depending on } \\
\text { the physiological } \\
\text { circumstances and cell } \\
\text { type. Tumor suppressor }\end{array}$ & 16.3 & N/A & N/A & N/A \\
\hline TTN & Titin & $2 q 31.2$ & $\begin{array}{l}\text { Nucleic acid binding } \\
\text { and identical } \\
\text { protein binding }\end{array}$ & $\begin{array}{l}\text { Key component in the } \\
\text { assembly and functioning } \\
\text { of vertebrate } \\
\text { striated muscles }\end{array}$ & 14.0 & N/A & N/A & N/A \\
\hline LATS2 & $\begin{array}{l}\text { Large Tumor } \\
\text { Suppressor } \\
\text { Kinase } 2\end{array}$ & $13 q 12.11$ & $\begin{array}{l}\text { Transferase activity, } \\
\text { transferring } \\
\text { phosphorus-containing } \\
\text { groups and protein } \\
\text { tyrosine kinase activity }\end{array}$ & $\begin{array}{l}\text { Negative regulator of } \\
\text { YAP1 in the Hippo } \\
\text { signaling pathway that } \\
\text { plays a pivotal role in } \\
\text { organ size control and } \\
\text { tumor suppression by } \\
\text { restricting proliferation } \\
\text { and promoting apoptosis. } \\
\text { Tumor suppressor }\end{array}$ & 9.3 & 1.1 & HOMDEL & N/A \\
\hline
\end{tabular}


Table 1. Cont.

\begin{tabular}{|c|c|c|c|c|c|c|c|c|}
\hline Gene Symbol & Gene Name & $\begin{array}{l}\text { Chromosomal } \\
\text { Location }\end{array}$ & GO Annotation & Molecular Function & $\begin{array}{c}\text { Mutation } \\
\text { Frequency (\%) }\end{array}$ & $\begin{array}{c}\text { CNA } \\
\text { Frequency (\%) }\end{array}$ & CNA Type & $\begin{array}{c}\text { Fusion } \\
\text { Frequency (\%) }\end{array}$ \\
\hline SETD2 & $\begin{array}{c}\text { SET domain } \\
\text { containing 2, } \\
\text { histone lysine } \\
\text { methyltransferase }\end{array}$ & $3 p 21.31$ & $\begin{array}{c}\text { Histone-lysine } \\
\mathrm{N} \text {-methyltransferase } \\
\text { activity }\end{array}$ & $\begin{array}{c}\text { Histone } \\
\text { methyltransferase that } \\
\text { specifically trimethylates } \\
\text { H3K36me3 using } \\
\text { H3K36me2 as substrate. } \\
\text { Tumor suppressor }\end{array}$ & 9.3 & 3.4 & HOMDEL & 3.5 \\
\hline PTCH1 & Patched 1 & $9 \mathrm{q} 22.32$ & Cholesterol binding & $\begin{array}{l}\text { Acts as a receptor for } \\
\text { secreted hedgehog } \\
\text { ligands. Tumor suppressor }\end{array}$ & 4.7 & N/A & N/A & N/A \\
\hline FAT4 & $\begin{array}{l}\text { FAT Atypical } \\
\text { Cadherin } 4\end{array}$ & $4 q 28.1$ & Calcium ion binding & $\begin{array}{l}\text { Plays a role in the } \\
\text { maintenance of planar } \\
\text { cell polarity as well as in } \\
\text { inhibition of } \\
\text { YAP1-mediated } \\
\text { neuroprogenitor cell } \\
\text { proliferation and } \\
\text { differentiation. } \\
\text { Tumor suppressor }\end{array}$ & 4.7 & 1.1 & HOMDEL & N/A \\
\hline FLG & Filaggrin & $1 \mathrm{q} 21.3$ & $\begin{array}{l}\text { Calcium ion binding } \\
\text { and structural } \\
\text { molecule activity. }\end{array}$ & $\begin{array}{l}\text { Aggregates keratin } \\
\text { intermediate filaments } \\
\text { and promotes } \\
\text { disulfide-bond formation } \\
\text { among the intermediate } \\
\text { filaments during terminal } \\
\text { differentiation of } \\
\text { mammalian epidermis. }\end{array}$ & 3.5 & 1.1 & AMP & N/A \\
\hline LRP4 & $\begin{array}{l}\text { LDL Receptor } \\
\text { Related Protein } 4\end{array}$ & $11 \mathrm{p} 11.2$ & $\begin{array}{l}\text { Calcium ion binding } \\
\text { and scaffold } \\
\text { protein binding }\end{array}$ & $\begin{array}{c}\text { Functions as a specific } \\
\text { facilitator of } \\
\text { SOST-mediated } \\
\text { inhibition of } \\
\text { Wnt signaling. }\end{array}$ & 3.5 & $\mathrm{~N} / \mathrm{A}$ & N/A & N/A \\
\hline
\end{tabular}


Pathological angiogenesis is a key mechanism in cancer cell proliferation, invasion, and metastasis, and is thus a hallmark of cancer [101]. Likewise, deregulated angiogenesis is an integral component of the highly aggressive behavior, and the chemotherapy-resistant nature of MPM [102,103]. This has been obtrusive by way of augmented expression of HIF- $1 \alpha$ (hypoxia-inducible factor $1 \alpha$ ) and elevated blood neovascularization as measured via vessel density $[104,105]$. Furthermore, deregulations in master regulators of angiogenesis, which include increased expression of VEGF (vascular endothelial growth factor) family proteins and their specific receptors (VEGFRs), and the downstream targets of VEGF/VEGFR signaling axis, mainly the RTK signaling mediators PKC (protein kinase C) and Akt, have been implicated in MPM tumorigenesis [106]. Similarly, deregulation of FGF and PDGF pathways by virtue of autocrine and paracrine signaling, have been associated with MPM cell survival and angiogenesis [107]. Despite the negative results with earlier antiangiogenic therapies, newly designed clinical studies targeting VEGF and other growth factor signaling pathways, alone or in combination, are underway [105].

Frequent acquisition of genome-wide copy number alterations in MPM is linked to impaired microtubule and spindle dynamics and chromosome segregation, a key aspect of accurate cell cycle regulation and genome stability. The condensin complex, kinesin family proteins (KIFs), cyclins, and the MSAC (mitotic spindle assembly checkpoint) pathway regulate precise spindle organization and chromosome segregation during cell division [108-111]. While no mutations had been identified, important deregulations of these molecular networks were reported. Specifically, CNAP1, NCAPD3, and BRRN1 of the condensin complex, cyclin genes (CCNA2, CCNB1, CCNB2, and CCNL2), and kinesin family genes (KIF14, KIF23, KIFC1, and KIF4A) were significantly elevated in MPM [112]. Further studies have depicted increased expression of BUB1 (BUB1 mitotic checkpoint serine/threonine-protein kinase) and MAD2L1 (mitotic arrest deficient 2 like 1), the essential components of the MSAC pathway, which reportedly predicted poor prognosis in MPM [113]. Other MSAC components, such as cell cycle-regulated serine/threonine Aurora kinase family members AURKA and AURKB, and Survivin (also called baculoviral inhibitor of apoptosis repeat-containing 5 or BIRC5), which function in centrosome maturation and cytokinesis progression, were found upregulated and associated with poor outcomes [113]. These findings indicate that targeting the components of the microtubule network in MPM might be a viable option.

The epithelial-mesenchymal transition (EMT) is a vital cellular program wherein epithelial cells lose their polarized epithelial phenotype and acquire features inherent to mesenchymal-like cells, characterized by increased expression of extracellular matrix (ECM) proteins, enhanced motility, invasiveness, metastasis, and resistance to apoptosis [114]. The EMT process plays an essential role in MPM pathogenesis and is associated with high-grade malignancy, thus poor prognosis. In this regard, while the epithelioid subtype displays features of epithelial cells, the sarcomatoid and biphasic histological subtypes are usually recognized as mesenchymal and intermediate phenotypes, respectively [115]. Many genes associated with reprogramming of cell-cell and cell-extracellular matrix interactions orchestrated by means of the EMT process are differentially expressed in MPM and correlate with worse survival. Interestingly, a substantial number of these genes such as matrix metalloproteases ( $M M P 3, M M P 7$, and MMP14), integrins, and a group of cytoskeletal proteins and cell adhesion molecules (ITGA3, ITGB4, VCAN, VIM, PECAM1, CDH1, CDH5, and CD44), structural molecules, and modifiers of ECM (LOXL2, BNC1, GREM-1, FBN2, THBS2, RASGRP3, ANXA6, ADAMTS6, and ADAM19) and transcription factors (SNAI1, SNAI2, ZEB1, TWIST1, and HMGA2) are either significantly enriched in the gene signature or recognized as signaling modulators of the TGF- $\beta$ (transforming growth factor $\beta$ ) pathway [19,62,112,116-122]. Indeed, a large body of evidence that accumulated over the last few years, suggests that the TGF- $\beta$ signaling pathway is dysregulated in MPM. Thereof, a less favorable prognostic association has been identified between the EMT score of MPM and the activated TGF- $\beta$ gene signature $[119,123]$. Taken together, further studies may provide the basis for assessing TGF- $\beta$ pathway-specific inhibitors for targeted therapy in MPM, at least in those with high EMT scores. 
A comprehensive genomic analysis has recently studied the differential gene expression profiles of 216 human primary MPM samples and their matched normal counterparts, one of the largest cohorts in recent years. RNA sequencing results identified a total of 430 differentially expressed genes: 189 upregulated and 241 downregulated. Consistent with previous reports, the EMT gene signature was able to define distinct molecular subgroups of MPMs. The most significantly upregulated mesothelial marker genes in the epithelial group included cytoskeleton, transmembrane, cell junction and, extracellular matrix assembly genes, e.g., ELMO3, MSLN, ITLN1, SYT4, UPK3B, CLDN15, LRRN4, RSPO1, VTN, and KLK11. On the contrary, EMT-positive marker genes, e.g., LOXL2, VIM, ADAMTS6, $C D H 13, C D H 17, S N A I 2$, and HMGA2, were among the most significantly upregulated genes in the sarcomatoid group. Even though the functional role of many of these genes in MPM pathophysiology is yet to be confirmed, their differential expression could serve as a diagnostic, and therapeutic tool [23]. Remarkably, the expression ratio between the Claudin family gene CLDN15, which is normally downregulated in cells undergoing EMT, and the VIM gene, a marker for the mesenchymal state, was a significant discriminating signature between subgroups [124]. Observations like these indicate that incorporating genetic mutation profiles with gene expression deregulations would enable the identification of actionable alterations and facilitate the development of targeted therapies.

\subsection{Epigenetic Deregulations}

Functional deregulations in epigenetic modifications such as DNA methylation, post-translational histone modifications, and chromatin remodeling play diverse and critical roles in carcinogenesis. Molecular studies in MPM have identified aberrant epigenetic events affecting the pathogenesis of the disease. An early study by Christensen et al. compared the causality between asbestos exposure and epigenetic aberrations of MPM by particularly focusing on the promoter CpG methylation patterns of select tumor suppressor genes. A significant correlation between the asbestos burden and the methylation status of CDKN2A, CDKN2B, APC, and RASSF1 tumor suppressor genes has been identified [125]. Consistent with their preceding report, Christensen et al. later noted that the global methylome profiles could effectively differentiate the normal pleura tissue from the malignant state and that they were predictors of patient survival [126]. Later, Goto et al. cross-compared epigenetic profiles of MPM and lung adenocarcinoma samples where high throughput analysis identified an average number of 387 hypermethylated genes in MPM samples vs 544 genes in lung adenocarcinoma. Among these genes, TMEM30B, KAZALD1, and MAPK13 were specifically methylated in MPM tissues and have been proposed as putative diagnostic markers. Besides, a lower frequency of DNA hypermethylation has significantly correlated with a better clinical outcome [127]. Of particular interest, the authors of this study postulated that the two malignancies had distinct epimutation mechanisms, mainly induced by asbestos vs. smoking. In addition, the epigenetic silencing of SFRP2 and SFRP5 tumor suppressor genes, which encode secreted frizzled related proteins, has been observed in MPM samples [128]. These findings are of particular significance for two reasons: First, the promoter methylation profile of these genes could potentially serve as a plasma-based epigenetic biomarker. Second, SFRPs are antagonistic modulators of the Wnt signaling, and their downregulation via hypermethylation could, in part, explain the aberrant activation of the Wnt pathway in MPMs.

Recent studies have identified that methylation-mediated global dynamic changes in the transcriptome are correlated with increased expression of DNA methyltransferase genes, namely DNMT1, DNMT3A, and DNMT3B. Besides, the increased expression of these genes has been associated with shorter survival of MPM patients [129]. Other dynamic mechanisms of epigenetic modifications involve the acetylation and methylation of histones, and chromatin remodeling. The study by Goto et al. defined that a number of genes silenced in MPM samples were enriched for the repressive histone H3 lysine methylation (H3K27me3) mark [127], which is a downstream target of PRC2 (the polycomb repressive complex 2). Experimental evidence further indicated that increased H3K27me3 marks were associated with concomitant overexpression of EZH2 (enhancer of zeste homolog 2) and SUZ12 (SUZ12 polycomb repressive complex 2 subunit) which, by forming the PRC2 complex, contribute 
to tri-methylation of histone 3 lysine 27. Additional work revealed that increased expression of EZH2 and SUZ12 correlated with poor survival, highlighting the potential of therapeutic targeting of these deregulations in MPM [129]. In addition, Lafave et al. demonstrated that the loss of BAP1 in mice resulted in increased H3K27me3 and elevated expression of EZH2. Furthermore, pharmacological inhibition of EZH2 in BAP1-mutant MPM cell lines abrogated their growth in vitro and in vivo, suggesting that EZH2 could represent a genotype-specific vulnerability in MPM [130]. In strong support of these findings, Tazemostat, a first-in-class small-molecule inhibitor of EZH2 received accelerated FDA approval in January 2020 for the treatment of locally advanced or metastatic epithelioid sarcoma [131]. More importantly, it is currently undergoing clinical development for use in other tumor types, including MPM.

\subsection{Deregulations of Non-Coding RNAs}

Recent advances in RNA sequencing technology have revealed that only $1-2 \%$ of the human genome codes for proteins and the vast majority of the transcribed genome is composed of non-coding RNAs (ncRNAs) $[132,133]$. Although not translated into proteins, ncRNAs have been shown to play multidimensional roles in a wide range of biological processes such as activation or repression of transcription, regulation of mRNA translation, post-translational modifications, and chromatin remodeling $[134,135]$. Compelling experimental evidence suggests that ncRNAs have a profound impact on cancer hallmarks. Accordingly, their expression is frequently deregulated in carcinogenesis $[136,137]$. Two subclasses-microRNAs (miRNAs) and long non-coding RNAs (lncRNAs) - have been demonstrated to play important roles in cancer cell biology with tumor suppressor or oncogenic functions. Supported by extensive experimental evidence, ncRNAs possess potential clinical relevance as diagnostic biomarkers and molecular targets for many cancers including thoracic malignancies such as lung cancer and MPM [138-140]. Earlier MPM research on miRNAs and lncRNAs have been extensively reviewed elsewhere by Reid et al. and Singh et al., respectively [141,142]. Importantly, many significant studies on ncRNAs have been published after these reviews. Table 2 lists the most recent MPM studies on ncRNAs. 
Table 2. Dysregulated ncRNAs with biological activity in MPM. N/A: data not available.

\begin{tabular}{|c|c|c|c|c|c|}
\hline Name of the ncRNA & Sample Type & Deregulation & Value & Functions & References \\
\hline $\begin{array}{l}\text { miR-98, miR-1271, } \\
\text { miR-128, miR-143, miR-28, } \\
\text { miR-3607, miR-500a, } \\
\text { miR-532 }\end{array}$ & Tumor Samples & Downregulation & Prognostic & $\begin{array}{l}\text { These miRNAs are downregulated in } \\
\text { asbestos-exposed group compared to } \\
\text { non-exposed MPM patients. } \\
\text { High expression of only miR- } 98 \text { was } \\
\text { significantly associated with poor prognosis } \\
\text { in patients with asbestos-exposed MPM. }\end{array}$ & [143] \\
\hline $\begin{array}{l}\text { miR-200c, miR-210, } \\
\text { miR-143 }\end{array}$ & Pleural Effusions & Upregulation/downregulation & Biomarker & $\begin{array}{l}\text { Upregulation of miR-210 and } \\
\text { downregulation of miR-200c and miR-143 } \\
\text { are potential PE cell biomarkers for } \\
\text { differentiating MPM from benign and } \\
\text { malignant PE-causing diseases. }\end{array}$ & [144] \\
\hline miR-566 & Cell Lines & High expression & Prognostic & $\begin{array}{c}\text { Increased miR-566 expression was } \\
\text { significantly associated with higher MT } \\
\text { protein level which is related with } \\
\text { drug resistance. }\end{array}$ & [140] \\
\hline miR-548a-3p, miR-20a & Serum & High expression & Biomarker & $\begin{array}{l}\text { Sera miRNA-548a-3p and miR-20a are } \\
\text { elevated in MPM patients compared with } \\
\text { cancer-free controls. }\end{array}$ & [145] \\
\hline miR-137 & $\begin{array}{l}\text { Tumor Samples and } \\
\text { Cell Lines }\end{array}$ & $\begin{array}{l}\text { Variable expression-mostly } \\
\text { high expression }\end{array}$ & Prognostic & $\begin{array}{l}\text { High miR-137 expression is associated with } \\
\text { poor patient outcome. Increased miR-137 } \\
\text { levels by mimic transfection suppressed } \\
\text { MPM cell growth and colony formation and } \\
\text { reduced invasion by targeting YBX1. }\end{array}$ & [147] \\
\hline miR-2053 & Serum & High expression & Prognostic & $\begin{array}{l}\text { Kaplan and Meier analysis revealed a } \\
\text { significant increase in PFS (progression free } \\
\text { survival) and decrease in cumulative hazards } \\
\text { among miR-2053 positive MPM patients. }\end{array}$ & [148] \\
\hline lncRNA-RP1-86D1.3 & Serum & High expression & $\mathrm{N} / \mathrm{A}$ & $\begin{array}{l}\text { Had higher expression in MPM compared to } \\
\text { benign and healthy control group. }\end{array}$ & [148] \\
\hline
\end{tabular}




\section{Functional Genomics of Malignant Pleural Mesothelioma}

Functional genomics aims to uncover the relationship between genetic aberrations and phenotypic characteristics of the disease, the ultimate goal of which is to translate the findings into clinical applications. The invention of a series of rapidly evolving large-scale genomic and transcriptomic sequencing technologies facilitated the detection and identification of novel mutations and gene expression deregulations in cancer. Indeed, by combining both "gene-by-gene", which we refer to as low throughput here, and high-throughput studies with functional genomics tools, such as RNAi and CRISPR, researchers were able to execute the global characterization of complex relationships between the genotype and the phenotype. Even though the number of functional genomics studies in MPM is limited, the available literature successfully validates the functional aspects of numerous genetic alterations that are significantly associated with biological processes including transcription, signal transduction, cell division, and migration. Experimental models used in these studies include established cancer cell lines, next-generation cell culture systems, and animal models. In this section of the review, we summarize the MPM literature with a particular focus on functional genomics studies with diagnostic, prognostic, and therapeutic implications (Figure 1).

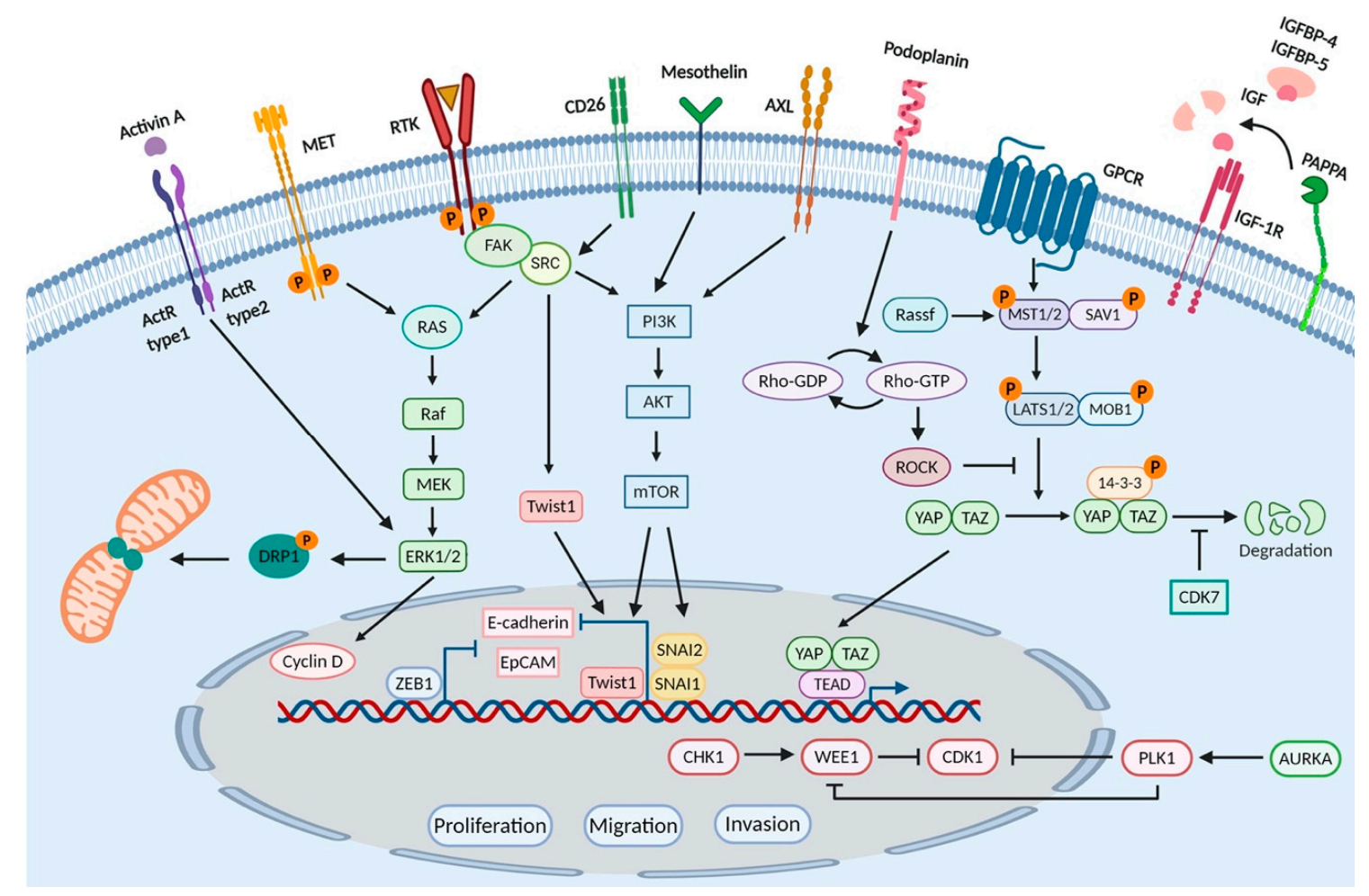

Figure 1. An outline of molecular mechanisms implicated in MPM pathogenesis through functional genomics studies.

\subsection{Low-Throughput Functional Studies}

Historically, the "gene-by-gene" approach in low-throughput functional studies has been very common in cancer research. These studies have made remarkable contributions to the identification of certain cancer-associated genes/pathways with relevance to specific biological processes and disease states. Referring to them, here we provide a summary of RNAi-based loss of function studies in MPM.

Membrane proteins along with heterotypic signaling molecules are key players in intercellular communication and signal transduction. Based on their biological function, membrane proteins can be grouped as receptors, cell adhesion molecules, glycosylphosphatidylinositol (GPI)- and lipid-anchored proteins, transporters, and cell membrane-associated enzymes. Alterations in membrane proteins and, 
in some cases, their ligands have been associated with the progression of cancer [149]. In principle, all membrane proteins that are highly expressed in tumors have the potential to be utilized as diagnostic and prognostic biomarkers, and pharmaceutical targets. Receptor tyrosine kinases (RTKs) and the downstream molecules that convey signal transduction processes play crucial roles in cellular homeostasis and are amenable to deregulation in cancer. Indeed, mutations in the RTKs have been identified in several cancers [150], and an increasing body of evidence has emphasized their dysregulation in MPM $[97,151,152]$. In particular, the knockdown of known RTKs such as AXL, EPHB2 (Ephrin B2 receptor), and MET by RNAi (mainly shRNA) or inhibition by small-molecule inhibitors led to a marked reduction in cell viability and migration capacity [153-155]. Specifically, the AXL inhibitor was shown to block the interaction between the AXL and PI3K pathways resulting in the disruption of the PI3K/Akt/mTOR signaling, a rationale granting the evaluation of AXL inhibition as a therapeutic strategy against the clinical progression of MPM [153]. Moreover, Wang et al. has recently reported that silencing of MET expression via siRNA or pharmacological inhibition of its activity attenuated the viability and migration capacity of MPM cells in vitro and significantly impeded tumor growth in vivo. Mechanistically, this was explained by dephosphorylation of DRP1 (dynamin related protein), a key component of mitochondrial and peroxisomal division machinery, uncovering a novel mechanism of mitochondrial regulation by the crosstalk between DRP1 and MET pathways. Given these promising findings, further evaluation of combinatorial inhibition of MET signaling and DRP1 activity in MPM is warranted [155].

Similar to RTKs, receptor serine/threonine kinases (RSTKs), also known as activin receptors or activin-receptor-like kinases, are critical mediators of a wide array of cellular events such as proliferation, apoptosis, differentiation, and migration and play a role in the pathogenesis of many diseases, including cancer [156]. In MPM, Hoda et al. studied the dependency of MPM cell lines to activin receptor activity as well as the activins, members of TGF- $\beta$ superfamily of secreted polypeptide growth factors. Their work showed that activin A was highly expressed in epithelioid phenotype and silencing of activin $\beta$ A expression by siRNA attenuated cell viability and clonogenicity of MPM cell lines. Moreover, selective small molecule inhibition of type I activin receptors resulted in impaired growth, clonogenicity, and migration of MPM cell lines. Possible mechanisms underlying these observations included reduced expression of Cyclin D1 and Cyclin D3 and decreased phosphorylation of ERK1/2 [157]. Similarly, Tamminen et al. showed that all MPM samples tested in their study scored high immunoreactivity for activin A and activin B. Moreover, their independent work confirmed that ERK activation was required for activin A-induced motility and invasion of MPM cells [158]. Conclusively, individual or combinatorial inhibition of activins, activin-receptor-like kinases, and ERK pathway evokes a therapeutic window against MPM.

CD26 is a type II transmembrane glycoprotein and is related with high proliferative activity as well as invasiveness in MPM cells. The knockdown of CD26 resulted in a significant reduction of periostin, a secreted cell adhesion protein. Similarly, p-Src levels and the expression of the transcription factor Twist, a regulator of periostin expression downstream of c-Src pathway, were significantly reduced upon CD26 silencing, revealing the mechanism of CD26-associated upregulation of periostin wherein increased secretion of periostin resulted in the enhanced migratory and invasive activity of MPM cells [159].

In the study by Ishiguro et al., activated leukocyte cell-adhesion molecule (ALCAM/CD166), which is also a cancer stem cell marker, has been shown to be highly expressed in MPM. Mechanistically, ALCAM enhanced the malignant features of mesothelioma cells and positively contributed to MPM progression. As exemplified by the efforts to study its function, silencing of ALCAM led to the inhibition of cell migration and invasion, and impaired anchorage-independent cell growth without affecting cell proliferation. Similarly, the administration of a purified and soluble form of ALCAM, namely, sALCAM, which is known to block homophilic binding of ALCAM, attenuated cell migration and invasion, and inhibited anchorage-independent cell growth in vitro. Similarly, subcutaneous 
tumors formed by the inoculation of the MPM cell line expressing sALCAM resulted in significantly prolonged survival in mice, offering therapeutic utility of this cell adhesion molecule in MPM [160].

Podoplanin, a well-conserved type-I transmembrane sialomucin-type glycoprotein encoded by the PDPN gene, is emerging as a candidate biomarker characterized by elevated expression in MPM. The knockdown of PDPN expression by siRNA or shRNA in cell lines expressing high levels of Podoplanin inhibited cell motility and resulted in decreased Rho-GTP binding. Reciprocally, ectopic expression of PDPN enhanced cell motility and resulted in increased Rho-GTP binding, evoking a motility promoting role for PDPN in MPM via the regulation of RhoA/ROCK pathway activity. Finally, a variety of modalities tailored to target both intracellular and extracellular domains of Podoplanin have demonstrated promising results in many cancers including MPM [161].

Mesothelin, a GPI-anchored plasma membrane differentiation antigen encoded by the MSLN gene, is often overexpressed in MPM patients. Because of its limited expression in normal tissues, mesothelin exhibits high specificity for malignancy. More importantly, mesothelin breaks down in the pleural cavity into smaller soluble proteins known as soluble mesothelin-related peptides (SMRPs) which can be detected in serum samples. These attributes granted mesothelin the Food and Drug Administration (FDA) approval for the diagnosis of MPM. Of particular interest, mesothelin is also being investigated as a therapeutic target. Recent work by He et al. has shown that the knockdown of MSLN expression by shRNA inhibited cell growth, colony formation, tumorsphere formation, migration, and invasion in vitro and reduced tumor formation and metastasis in vivo. Besides, the inactivation of mesothelin resulted in the upregulation and downregulation of several EMT markers (CDH1 and CAV2) and stem cell specific genes (TWIST, SNAI1, SNAI2, and ABCG2), respectively, revealing its role in the regulation of the EMT process and cancer stem cell traits [162]. Further studies in a clinically relevant orthotopic mouse model that recapitulated the MPM biology showed that the ectopic overexpression of mesothelin promoted tumor invasion and significantly decreased survival, compared to mice with MSLN-negative tumors. This effect of mesothelin was attributed to increased expression and concomitant secretion and colocalization of MMPs, especially MMP-9, with mesothelin which substantiated the biological role of mesothelin as a promoter of tumor invasion and highlighted the translational relevance of these findings [163].

To date, several studies have shown that the activation of the Hippo pathway and the YAP protein are important in MPM, and enhanced oncogenic activity of YAP has been associated with poor prognosis. The inhibition of YAP by siRNAs or Verteporfin, a YAP-specific inhibitor, significantly suppressed invasion and tumorsphere formation of MPM cells by repressing downstream gene transcription of the Hippo kinase cascade, suggesting that MPMswith aberrant YAP activity could be sensitive to Verteporfin therapy [164]. In addition, the inactivation of RhoA/ROCK signaling by siRNAs or GSK269962A, a selective ROCK inhibitor, decreased YAP transcriptional activity and the viability of MPM cells [164]. Furthermore, CDK7 (cyclin-dependent kinase 7), a serine/threonine protein kinase, can sustain Hippo signaling by directly phosphorylating and protecting YAP from ubiquitination and degradation [165]. In a study by Mioa et al., the inhibition of CDK7 by siRNAs downregulated YAP expression via promoting its degradation and suppressed the invasion and tumorsphere formation capacity of MPM cells [166]. As their druggability potential has been assessed positively in other cancer types, the results of these studies suggest that RhoA/ROCK pathway and CDK7 represent therapeutically actionable targets in MPM as well.

MPM is certainly an aggressive cancer characterized by increased migration and subsequent invasion and metastasis into other tissues and organs. In an attempt to identify the genes that are related to MPM cell migration, Huang et al. investigated the migration capacity and gene expression profiles of MPM cell lines and determined that several genes have had relatively high correlation with migration. For example, the increased expression of pappalysin 1, a secreted metalloprotease encoded by the PAPPA gene which selectively cleaves insulin-like growth factor binding proteins (IGFBP-4 and IGFBP-5), positively correlated with the augmented migratory capacity of MPM cell lines. As expected, the enhanced cellular migration was associated with the proteolysis of IGFBP-4 by pappalysin 1 and 
the subsequent release of IGF-1 as a chemotactic factor. Furthermore, siRNA- or shRNA-mediated silencing of PAPPA led to inhibition of migration and proliferation of MPM cells and inhibited tumor growth in mouse orthotopic xenograft models, suggesting that pappalysin 1 could represent a potential therapeutic target [167].

Transcription factors are generally deregulated in carcinogenesis and are potential targets for cancer therapy [168]. Functional consequences of deregulations in ZEB1, ER $\beta$, SP1, and WT1 zinc-finger transcription factors are well studied in breast cancer, lung cancer, pancreatic cancer, and prostate cancer [169-172]. Recently, the upregulation of these genes has been shown in MPM, when compared to matched normal counterparts [173-176]. Horio et al. showed that siRNA-mediated knockdown of ZEB1 (zinc finger e-box binding homeobox 1) led to the suppression of proliferation, and anchorage-dependent and anchorage-independent clonal growth of MPM cells. Besides, the stable knockdown with a retroviral shRNA-expressing vector resulted in transcriptional derepression of E-cadherin and EpCAM, thus mesenchymal-to-epithelial (MET) transition. The findings of this study suggest that ZEB1 may serve as a promising therapeutic target in MPM [177]. In line with this, the knockdown of estrogen receptor beta (ER $\beta$ ) in ER-positive REN cell line, an MPM cell line with epithelioid histotype, resulted in increased EGFR, Akt, and ERK1/2 phosphorylation, and promoted proliferation. Additionally, ER $\beta$ colocalized with EGFR in Caveolin 1-enriched membrane fractions leading to delayed internalization of ER $\beta$ by interfering with EGFR phosphorylation. Suggestive of a therapeutic role, ER $\beta$ silencing sensitized REN cells to Gefitinib treatment [178]. In the study by Rao et al., shRNA-mediated knockdown of SP1 (Sp1 transcription factor) inhibited the growth, migration, and tumorigenicity of MPM cells, imposing an oncogenic function for SP1 in MPM. Additionally, treatment with mithramycin (MM), an anti-neoplastic agent that inhibits binding of SP1 to DNA, decreased SP1 expression and inhibited the proliferation and clonogenicity of MPM cells in vitro, and tumorigenicity in vivo [175]. The knockdown of WT1 (Wilms Tumor Protein 1), another transcription factor highly expressed in MPM, greatly reduced the proliferation, chemotaxis, and invasion of MPM cells. Although not significantly, WT1 knockdown improved chemosensitivity to cisplatin treatment, granting the necessity for additional studies [179].

Pemetrexed is an anticancer chemotherapy drug used in the treatment of MPM. Unfortunately, about half of the tumors are inherently chemoresistant, limiting the wide application of that antifolate small molecule. The resistance to pemetrexed has been largely attributed to the increased expression of the thymidylate synthase (TS) enzyme, a folate-dependent enzyme responsible for the conversion of deoxyuridine monophosphate (dUMP) to deoxythymidine monophosphate (dTMP), a rate-limiting step in DNA synthesis. Abu Lila et al. investigated the effect of the downregulation of TS gene on the cytotoxic efficacy of pemetrexed against MPM. Combined treatment of human MPM cell line representing biphasic subtype, MSTO-211H, with TS-specific shRNA and pemetrexed resulted in a remarkably higher cytotoxicity when compared to pemetrexed alone. Similar results were obtained in vivo where doublet combination treatment of orthotopic MSTO- $211 \mathrm{H}$ tumors, implanted in the thoracic cavity of nude mice, with TS shRNA and pemetrexed resulted in marked inhibition of tumor burden and improved overall survival [180]. In support of these findings, Monica et al. showed that dasatinib, a dual Bcr/Abl and SFK (the Src family of protein tyrosine kinases) competitive ATP inhibitor, sensitized MPM cell lines to pemetrexed treatment by reducing TS protein expression. Thus, the use of effective antifolate thymidylate synthase inhibitors in combination with pemetrexed regimens could represent a viable therapy option in MPM treatment [181].

\subsection{High-Throughput Functional Genomics Screens}

Often combined with a wide array of high throughput technologies, such as genome-wide RNAi and CRISPR screens as well as drug screening, functional cancer genomics studies entail the functional annotation of cancer-causing aberrations. 


\subsubsection{RNA Interference and CRISPR Screens}

The study by Sudo et al. marks the first large-scale loss of function RNAi screen conducted in MPM cells. The siRNA library used in this work consisted of nine sub-libraries, namely, ion binding, ion channel, kinase, membrane transporter, nucleic acid binding, phosphatase, receptor, transcription factor, and transporter, culminating to 8589 siRNAs in total. The study found that the knockdown of 78 genes caused suppression in the proliferation of MSTO- $211 \mathrm{H}$ cell line by at least $80 \%$. These genes were further validated in a secondary sub-library screen where COPA, COPB2, EIF3D, POLR2A, PSMA6, $R B M 8 A$, and RPL18A genes showed the greatest negative impact on cell viability. The authors then focused on COPA, a gene that encodes a subunit of the cargo complex that modulates retrograde protein trafficking from Golgi to the endoplasmic reticulum, for functional studies in vivo as it had been reported to have increased expression in MPM. Functional studies with MSTO-211H cell line revealed that the knockdown of COPA gene by siRNA suppressed tumor growth and induced apoptosis in vivo, suggesting that COPA could be a novel therapeutic target in MPM [182].

To identify novel genes with MPM-specific therapeutic relevance, Linton et al. selected 40 genes for functional studies. These genes were previously reported to be overexpressed in MPM $[183,184]$. In particular, the silencing of BIRC5, CDK1, CHEK1, NDC80, PLK1, RRM1, or RRM2 genes resulted in a profound reduction in cellular growth. The authors further evaluated the role of CDK1 (cyclin dependent kinase 1), NDC80 (kinetochore complex component), and PLK1 (polo like kinase 1) proteins in cell survival since they could be targeted by small-molecule inhibitors and have not been linked to MPM before. Indeed, treatment of a panel of human MPM cell lines (H28, MSTO-211H, MM05, and H226) with selective CDK1, NDC80, or PLK1 small-molecule inhibitors attenuated cell growth and colony formation. Additionally, small-molecule inhibitors of CDK1 and NDC80 increased cisplatin sensitivity of MPM cells [185]. In conclusion, this study showed that RNAi screens could be harnessed for the functional interrogation of genes on a large scale and help uncover new genes and signaling pathways with therapeutic implications in MPM.

The only frontline chemotherapy regimen approved for clinical use in advanced stage MPM is the combination of platin and pemetrexed. Unfortunately, only a small fraction of patients responds to this therapy and inevitably most cases develop drug resistance. A recent functional genomics study by $\mathrm{Xu}$ et al. has aimed to identify the genetic determinants that limit the efficacy of standard cisplatin/pemetrexed chemotherapy in MESO-1 cells by implementing a kinome-wide CRISPR negative selection screen strategy based on a lentiviral sgRNA library that targets 763 kinases. The screen revealed that 33 kinases were markedly depleted in cisplatin/pemetrexed-treated versus the vehicle control group. Six kinase genes, namely, WEE1, AURKA, MPP3, MAP3K12, DGKD, and SPEG, scored for the most significant screening criteria. Of note, the depletion of WEE1, a G2-M checkpoint kinase with therapeutic implications, showed the most remarkable negative effect on cell viability. Accordingly, the authors performed follow up experiments on WEE1 gene and demonstrated that CRISPR-based deletion of WEE1 sensitized MPM cells to cisplatin/pemetrexed treatment. More importantly, inhibition of WEE1 by a small-molecule inhibitor AZD1775 showed synergistic effects with chemotherapy agents by forcing a premature mitotic entry and led to enhanced MPM cell death in vitro, which was further harmonized by potent antitumor effects in vivo [186].

Very recently, Okonska et al. have performed a genome-wide synthetic lethality siRNA screen in H2452 cell line that was engineered to express either functional or nonfunctional BAP1. Thus, the aim was to define BAP1-dependent genetic vulnerabilities. The study identified 1775 genes, among which 191 genes were calculated to be significantly differentially lethal, when lethality score was set to $\geq 0.2$ between the BAP1-proficient vs BAP1-deficient cells. Interestingly, gene ontology analysis revealed that the most significantly enriched functional annotation group of these 191 genes was RNA splicing and processing. Furthermore, using a more stringent differential lethality score, the authors identified 11 genes whose depletion were specifically more cytotoxic in the BAP-proficient cells. From this cluster of 11 genes, RRM1 (ribonucleotide reductase catalytic subunit M1) and RRM2 (ribonucleotide reductase catalytic subunit M2) genes were selected for further characterization as they were deemed to have 
clinical relevance. Specifically, RRM1 and RRM2 subunits form the ribonucleotide reductase (RNR) protein heterotetramer complex, a key enzyme in dNTP synthesis that helps maintain DNA replication fidelity and genome stability. Noteworthy, the inhibition of elevated RNR activity by gemcitabine, alone or in combination with other drugs, has been exploited for second line therapy in MPM for many years. By measuring the sensitivity of a set of MPM cell lines to RRM1 and RRM2 inhibition both in two dimensional (2D) and three dimensional (3D) cell culture conditions, the authors found that BAP1-proficient cell lines (BAP1 wild type: H2052, ACC-Meso-1, Mero82, and SPC111) were more sensitive to this challenge, when compared to BAP-deficient cell lines (BAP1 mut/del: ACC-Meso-4, H226, and H2452). Similarly, the loss of function of BAP1 resulted in chemoresistance to RNR inhibition, suggesting that the BAP1 status may define a synthetically lethal genetic vulnerability, and could be a predictor of therapy response [187].

High-throughput RNAi and CRISPR screens provide a tremendous opportunity for the systematic characterization of cancer dependencies. However, they can be technically challenging to implement. While many high-throughput screens have been conducted in various human cancer cell lines, as outlined above, such studies are limited in MPM. Nevertheless, several resources are now available for public use which can help cancer researchers identify unique vulnerabilities and cancer-specific dependencies. One such resource is The Cancer Dependency Map (DepMap) portal [188,189], which was established through a collaboration between Broad Institute and Welcome Sanger Institute. With a commitment to Open Science, the DepMap, an ongoing project receiving frequent updates, provides free access to a wide range of information for more than 700 established cancer cell lines, including several MPM cell lines. Large datasets featured in the DepMap portal include cell line-specific genetic and transcriptomic profiles, sensitivity to small molecule perturbations, and genome-wide RNAi and CRISPR loss of function screens. To demonstrate the feasibility of this resource, here we performed a proof of principle analysis on select MPM cell lines. Using CRISPR (Avana) Public 20Q1 [190] and Combined RNAi datasets [191], we analyzed the common vulnerabilities of five MPM cell lines: H2052, H2452, H28, ACC-MESO-1, and MPP89. For this analysis, we defined the cut-off values as -1.5 and -0.75 for CRISPR and RNAi screen datasets, respectively. Following a manual curation, we found that among the genes with significant depletion scores DDB1, EEF2, EIF3A, HSPE1, RAN, RPS15A, RUVBL1, $S N R P D 1, U B A 1$, and $V C P$ genes were common in both datasets and all five cell lines. Encouragingly, all the genes obtained in this analysis have been previously listed as common essential genes [192], see Table 3 .

We further extended the analysis and investigated the mutational status of these genes in the TCGA dataset of 87 MPM cases. We found that DDB1 and EEF2 genes were amplified in two and one cases, respectively. Similarly, we determined that EIF3A and RUVBL1 genes were deleted in two individual cases suggesting that the genetic aberrations in these genes are infrequent. We hypothesized that for some, if not all, genes high dependency scores could be explained, in part, by gene expression alterations and overall survival profiles of MPM patients. To test this, we took the advantage of the intuitive, user-friendly interface of the GEPIA [193] and the UALCAN [194] web portals. This analysis revealed that the high expression levels of $R A N, R U V B L 1$, and SNRPD1 genes were significantly associated with lower overall survival rates (Figure 2). 
Table 3. Genomic and functional details on the common essential genes in MPM cell lines.

\begin{tabular}{|c|c|c|c|c|c|}
\hline Gene Symbol & Gene Name & Chromosomal Location & GO Annotation & Functions & Pathway/Superfamily \\
\hline DDB1 & $\begin{array}{l}\text { Damage Specific DNA } \\
\text { Binding Protein } 1\end{array}$ & 11q12.2 & $\begin{array}{l}\text { Nucleic acid binding and } \\
\text { damaged DNA binding }\end{array}$ & $\begin{array}{c}\text { Binds to DNA following UV damage } \\
\text { and functions in } \\
\text { nucleotide-excision repair }\end{array}$ & DDB1 gene family \\
\hline EIF3A & $\begin{array}{l}\text { Eukaryotic Translation } \\
\text { Initiation Factor } 3 \\
\text { Subunit A }\end{array}$ & $10 \mathrm{q} 26.11$ & $\begin{array}{l}\text { Translation initiation } \\
\text { factor activity }\end{array}$ & $\begin{array}{l}\text { Functions in the initiation of } \\
\text { protein synthesis }\end{array}$ & eIF-3 subunit A family \\
\hline HSPE1 & $\begin{array}{l}\text { Heat Shock Protein Family } \\
\text { E (Hsp10) Member } 1\end{array}$ & $2 \mathrm{q} 33.1$ & Chaperone binding & $\begin{array}{l}\text { Facilitates the correct folding of } \\
\text { imported proteins together with Hsp60 }\end{array}$ & GroES chaperonin family \\
\hline RAN & $\begin{array}{l}\text { RAN, Member RAS } \\
\text { Oncogene Family }\end{array}$ & $12 \mathrm{q} 24.33$ & GTP binding & $\begin{array}{c}\text { GTPase involved in } \\
\text { nucleocytoplasmic transport }\end{array}$ & RAS superfamily \\
\hline RPS15A & Ribosomal Protein S15a & $16 \mathrm{p} 12.3$ & $\begin{array}{l}\text { Structural constituent } \\
\text { of ribosome }\end{array}$ & $\begin{array}{l}\text { Structural component of } \\
\text { the ribosome. Oncogene }\end{array}$ & $\begin{array}{l}\text { Universal ribosomal } \\
\text { protein uS8 family }\end{array}$ \\
\hline RUVBL1 & RuvB Like AAA ATPase 1 & $3 q 21.3$ & $\begin{array}{l}\text { ATPase activity and DNA } \\
\text { helicase activity }\end{array}$ & $\begin{array}{c}\text { Possesses single-stranded } \\
\text { DNA-stimulated ATPase and } \\
\text { ATP-dependent DNA helicase } \\
\left(3^{\prime} \text { to } 5^{\prime}\right) \text { activity }\end{array}$ & $\begin{array}{l}\text { ATPases associated with } \\
\text { diverse cellular activities } \\
(\mathrm{AAA}+) \text { protein family }\end{array}$ \\
\hline SNRPD1 & $\begin{array}{l}\text { Small Nuclear } \\
\text { Ribonucleoprotein D1 } \\
\text { Polypeptide }\end{array}$ & $18 \mathrm{q} 11.2$ & RNA binding & $\begin{array}{c}\text { Plays role in pre-mRNA splicing as } \\
\text { core component of the SMN-Sm } \\
\text { complex and the spliceosomal U1, U2, } \\
\text { U4 and U5 snRNPs }\end{array}$ & $\begin{array}{l}\text { SNRNP core } \\
\text { protein family }\end{array}$ \\
\hline UBA1 & $\begin{array}{l}\text { Ubiquitin Like Modifier } \\
\text { Activating Enzyme } 1\end{array}$ & Xp11.3 & $\begin{array}{l}\text { Ubiquitin-like modifier } \\
\text { activating enzyme activity }\end{array}$ & $\begin{array}{l}\text { Catalyzes the first step in ubiquitin } \\
\text { conjugation to mark cellular proteins } \\
\text { for degradation through the } \\
\text { ubiquitin-proteasome system }\end{array}$ & $\begin{array}{l}\text { Ubiquitin-activating } \\
\text { E1 family }\end{array}$ \\
\hline $\mathrm{VCP}$ & $\begin{array}{l}\text { Valosin Containing } \\
\text { Protein }\end{array}$ & 9 p13.3 & $\begin{array}{l}\text { Signaling receptor } \\
\text { binding }\end{array}$ & $\begin{array}{l}\text { Necessary for the fragmentation of } \\
\text { Golgi stacks during mitosis and for } \\
\text { their reassembly after mitosis }\end{array}$ & AAA ATPase family \\
\hline
\end{tabular}



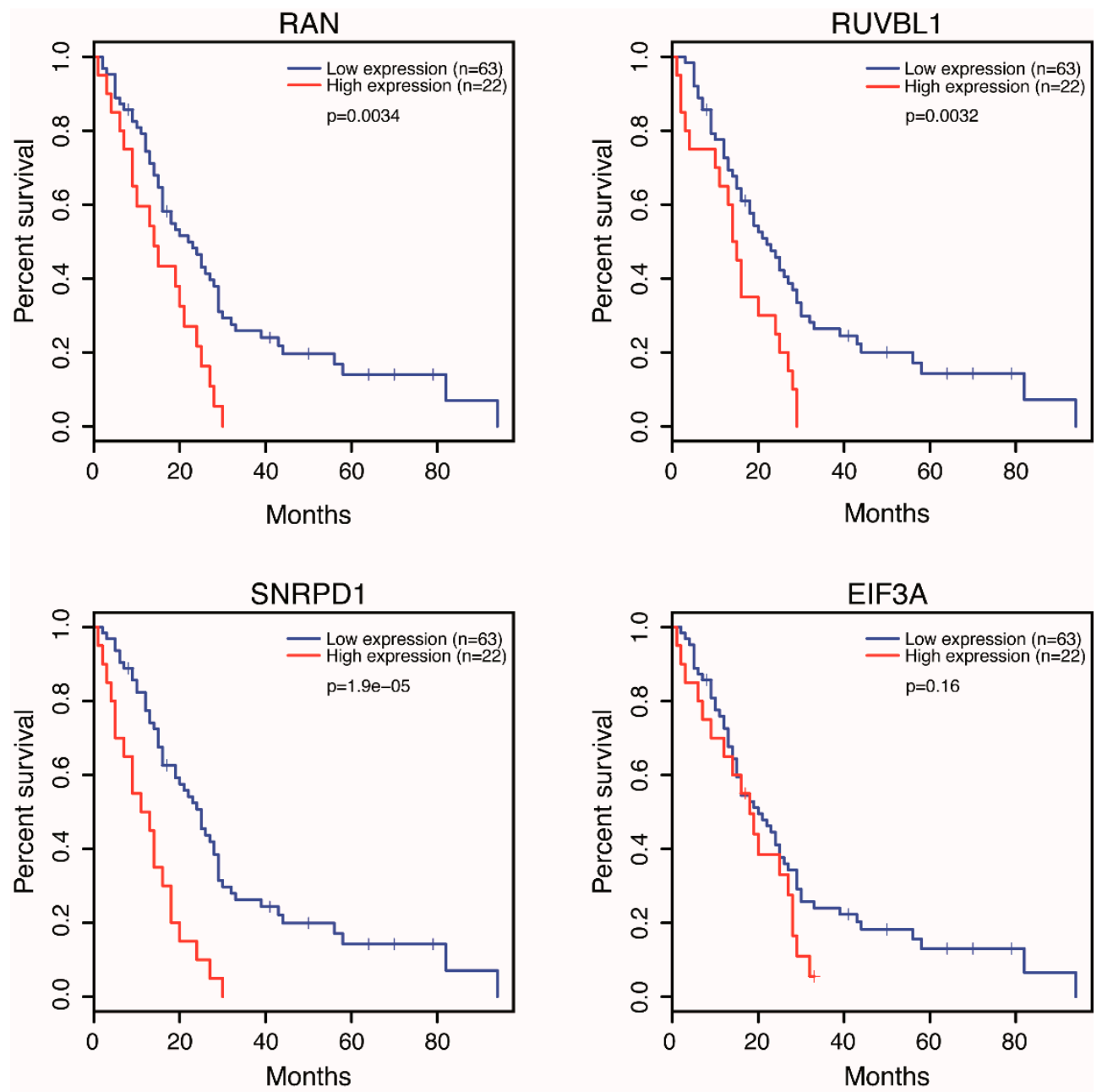

Figure 2. Overall survival rates of MPM patients according to low and high expression levels of select genes.

More importantly, among these 10 genes, the RAN gene, which encodes a small RAS superfamily GTP binding protein that is essential for a variety of nuclear processes, was highly expressed in and was proposed as a drug co-target against MPM [183]. A very recent study by Dell'Anno et al. also showed that siRNA-mediated depletion of RAN expression in MPM cell lines abrogated cellular growth and colony formation, suggesting that RAN signaling acts as a positive regulator of survival and proliferation in MPM [195]. Furthermore, the high expression levels of EIF3A gene seemed to correlate, although not significantly, with lower overall survival rates (Figure 1). Plus, an RNAi screen by Sudo $\mathrm{H}$ et al. showed that the knockdown of EIF3A reduced the viability of MPM cells, suggesting that further studies preferably on larger MPM cohorts, would be necessary to define a statistically significant correlation, if existing, between EIF3A expression and the overall survival of MPM patients [182]. In addition, the DepMap portal can also provide a top 10 preferentially essential genes list for each screened cell line. Unlike our manually curated gene list, that list is computed in a cell line-specific manner by subtracting the mean score of a specific gene across all cell lines, calculating the lowest mean-subtracted score of that gene for a given cell line. In conclusion, executing data curation based on different selection criteria can effectively provide scientists with distinct results that would complement their research interests.

As illustrated, a straightforward and systematic proof of principle approach based on the sequential use of various resources and computational tools enabled us to define a list of 10 common genes in CRISPR and RNAi screen datasets across all five cell lines. Among these, four genes were associated 
with MPM survival and two genes were previously linked to MPM, revealing that high throughput data presented through these portals can provide reliable sources for hypothesis development and testing, as well as generating preliminary data for functional studies. By leveraging other features of the DepMap project, researchers can further unveil the landscape of cancer vulnerabilities for therapeutic development and even identify biomarkers that predict them.

\subsubsection{Drug Screens}

MPM is a heterogeneous cancer with poor druggable biological targets. With an effort to study the efficacy of new drug candidates and regimens, researchers have employed high-throughput methods and tools in recent years. In a study by Quispel-Janssen et al., the researchers utilized a high throughput drug screen with 265 different chemical inhibitors in a panel of 889 cancer cell lines, including 19 MPM cell lines. Three of those MPM cell lines showed very high sensitivity to PD-173074, an FGFR1 and FGFR3 kinase inhibitor (FGFRi). This sensitivity was further confirmed by other more selective FGFR inhibitors, NVP-BGJ398, and AZD4547. Gene expression analysis of FGFRi-sensitive and FGFRi-resistant MPM cell lines revealed a remarkable correlation between elevated FGF9 mRNA expression and treatment response to PD-173074 and AZD4547. Notably, there was a significant correlation between loss of BAP1 expression, but not mutation status, and AZD4547 sensitivity. Further, AZD4547 treatment resulted in a significant growth inhibition in the FGFRi-sensitive MPM lines that were reconstituted from tumors, confirming the therapeutic potential of the FGFR pathway in a subset of MPM patients. Finally, the cell lines not responsive to FGFR inhibition were found synergistically sensitive to IGF1R and PI3K inhibition, suggesting that intrinsic resistance to FGFRi could be overcome by combinatorial therapies [196]. In a follow up study, the same group performed a large-scale drug screen consisting of seven common compounds (cisplatin, carboplatin, oxaliplatin, vinorelbine, gemcitabine, pemetrexed, and doxorubicin) and their combinations (cisplatin + pemetrexed, cisplatin + gemcitabine, carboplatin + pemetrexed, oxaliplatin + gemcitabine, and oxaliplatin + vinorelbine) on a set of 81 different primary cultures. Based on drug response rates, cultures were clustered into clinically relevant subgroups as the responders, nonresponders, and intermediate responders. To study the genomic basis of differential drug responses, RNA sequencing was performed. FGF9 and its receptors FGFR1 and FGFR3 were found to be upregulated in the nonresponders, in comparison to the responders. Correspondingly, the nonresponder primary cultures were found to be sensitive to the FGFR inhibitor, PD-173074. More importantly, in vitro drug responses of primary cultures were predictive of clinical responses to select drugs, suggesting that preliminary culture systems are suitable to identify mechanistic determinants of drug responses, and personalize treatment regimens [197].

\section{In Vitro and In Vivo Model Systems in Malignant Pleural Mesothelioma Research}

In the current MPM research, established and commercially available cell lines are frequently used in functional genomics studies. In general, 2D cell culture systems and the subcutaneous, and orthotopic xenograft models derived from them are suitable for the identification and functional validation of cellular, molecular, and genetic mechanisms of the disease, and the initial evaluation of potential antitumor agents. Yet there are various limitations associated with them. In particular, these models fail to completely recapitulate the genetic and phenotypic heterogeneity of the human disease, primarily the inflammatory nature, and intra- and inter-tumor heterogeneity of MPMs. Today, there is a growing interest in developing new experimental models for MPM studies, in particular in vitro next generation 3D cell culture systems such as organoids, in vivo preclinical tumor models such as patient-derived xenografts (PDX), and of course, genetically engineered mouse models (GEM) that can collectively facilitate the low and high throughput functional validation studies of genetic perturbations, assessment of drug responses, and identification of druggable targets [198-204].

Three dimensional MPM models provide many advantages over 2D cultures as they better represent the major in vivo characteristics of tumors. In a recent report, Mazzocchi et al. have collected surgical biospecimens from two human MPM patient tumors and generated a series of patient-derived 
organoids that accurately represented the disease and tissue heterogeneity. Furthermore, when integrated into a microfluidic organ-on-a-chip system to better mimic in vivo conditions, these MPM organoids were successfully used as a means to discover, with high clinical significance, patient-specific drug sensitivities, and predictive biomarkers against small molecules, demonstrating the remarkable capability of this platform to personalize and optimize treatment regimens [198]. The PDX models involve the collection of specimens from patient tumors and the successive subcutaneous implantation of these tissues or cells into immunocompromised or humanized mice. Notably, the PDX models retain the main pathohistological and genetic features of original tumor tissues and the associated stroma, to a lesser degree. A few years ago, Wu et al. attempted to establish the first large collection of PDX models from all histological subtypes. A total of 50 tumor samples were subcutaneously inoculated into flanks of NOD/SCID mice. Twenty of these were engrafted and passaged successfully for multiple generations. Further evaluation revealed that the PDX models effectively reflected the clinical heterogeneity of the respective parent tumors, and responded to Cisplatin treatment, proving the utility of these models to identify predictive biomarkers and evaluate the efficacy of treatment regimens [199].

As noted previously, oncogenic gain of function alterations seldom occurs in MPM. Rather, MPM is characterized by frequent genetic losses of CDKN2A, NF2, BAP1, and TP53 tumor suppressor genes. Accordingly, most of the MPM-specific GEM models, if not all, developed to date have focused on introducing these specific genetic aberrations of the human disease. To exemplify, Altomare et al. developed a model where repeated asbestos treatment of heterozygous NF2 mice induced rapid onset of MPM. Consistent with human malignancy, the tumors recapitulated the genetic and molecular features of MPM, characterized by the inactivation of the normal allele of the NF2 gene as well as frequent homozygous co-deletions of the CDKN2A and CDKN2B genes and the activation of Akt signaling. Collectively, this model is found to be practical for testing novel therapeutic strategies against growth and survival signaling pathways (e.g., the Akt pathway) implicated in this deadly disease [200].

Later, using a CRE-LoxP system by direct injection of Adenovirus expressing Cre recombinase (Adeno-Cre) into the pleural cavity of adult mice, Jongsma et al. developed compound mouse models carrying the combinations of conditional knockout alleles for NF2 and INK4A and/or TP53 that developed tumors with varying tumor latency, aggressiveness, and survival rates. As clearly stated by the investigators, this murine model may provide a mechanistic framework for the discovery of additional recurrent genetic alterations and unique gene expression deregulations. Besides, this model can help to explore novel molecular cues associated with MPM development and eventually enable the design of improved therapeutic strategies [201].

Recently, Sementino et al. have generated animal models to study the cooperation between PTEN and TP53 inactivation in MPM pathogenesis. Their study successfully demonstrated that the compound inactivation of PTEN and TP53 genes in mouse mesothelium, by intrathoracic injection of Adeno-Cre, could synergistically drive highly penetrant, rapid, and aggressive tumors, even in the absence of exposure to asbestos. Notably, this model can have translational implications because the TP53 gene is mutated in $\sim 15 \%$ of human MPMs and CDKN2A deletions, therefore the functional loss of the p14ARF protein, can also result in the deregulation of the p53 pathway. Moreover, the PI3K/Akt/mTOR pathway is activated in most human MPMs. Indeed, the tumors and the cell lines derived from this model were mainly characterized by genomic instability, upregulation of Myc, and hyperactivation of PI3K/Akt/mTor signaling. Although not feasible for testing therapeutic strategies aiming to reactivate TP53 and PTEN pathways, the rapid onset and short latency period of these tumor models and the frequent deregulation of therapeutically viable signaling pathways make this GEM model suitable for preclinical applications [202].

As shortly discussed earlier, individuals carrying germline mutations in the BAP1 gene are predisposed to MPM. Independent studies conducted in knockout animal models harboring germline heterozygous mutations (Bap1+/-) showed that these models could develop spontaneous tumors 
with low incidence. Furthermore, asbestos exposure of Bap1+/- animals resulted in accelerated, larger, and more aggressive tumor development with very high incidence and low survival rates. These findings were further supported by the accumulation of additional genetic aberrations such as the loss of the WT allele of the BAP1 gene and homozygous deletions of the CDKN2A and CDKN2B genes, recapitulating the features of human MPM pathology. The studies in these models proved that the $B A P 1$ gene was a bona fide tumor suppressor whose heterozygous germline mutation increases the risk of MPM development in BAP1 mutation carriers when exposed to environmental carcinogens, in particular asbestos fibers [205-207].

To understand the tumorigenic potential of the most frequently altered genetic lesions in MPM development, Badhai et al. have recently developed mouse models based on single and compound inactivation of tumor suppressor genes, namely $B A P 1, N F 2$, and CDKN2A and CDKN2B (CDKN2AB). In short, only the compound models $B A P 1, N F 2$, and $C D K N 2 A B$ (dubbed as BNC, combined deletion of $B A P 1, N F 2$, and $C D K N 2 A B$ ), and NF2 and CDKN2AB (dubbed as NC, combined deletion of NF2 and $C D K N 2 A B)$ developed highly aggressive tumors that recapitulated the histological and molecular characteristics of human patients, such as inflammatory microenvironment and gene expression profiles. More importantly, the BNC autochthonous tumors responded to and developed resistance against frontline chemotherapy agents with similar dynamics in human tumors. Similarly, the BNC tumors exhibited concurrent activation of MAPK and PI3K pathways and cell lines derived from these tumors were sensitive to PI3K inhibitor BEZ-235 [203]. Taken together, this model may be suitable for testing new treatment modalities including new immunotherapy concepts, screening synthetic lethal interactions, and investigating resistance mechanisms.

In another study by Kukuyan et al., the researchers created conditional homozygous knockout models of BAP1, NF2, and CDKN2A tumor suppressor genes based on intrathoracic injection of Adeno-Cre. Specifically, triple knockout animals developed highly invasive and proliferative tumors, predominantly with sarcomatoid histologic subtype, recapitulating the human MPMs. RNA sequencing analysis of triple knockout tumors displayed increased expression of genes previously implicated in BAP1 function. More importantly, when compared to NF2 and CDKN2A double knockout tumors where BAP1 expression was retained, many of the top differentially expressed genes in triple knockout tumors were downstream targets of PRC2, uncovering a connection between BAP1 and PRC2 and thereby confirming in vivo how, at least in part, the loss of BAP1 contributes to MPM pathogenesis [204].

\section{Conclusions and Future Challenges}

Clinical trials evaluating the efficacy of biologic agents that target key pathways and recurrent alterations in MPM failed to provide the expected results. A possible explanation to this failure may lie in the lack of oncogenic driver mutations in MPM, which instead characterize other types of cancer. Rather, the loss of tumor suppressor genes results in the simultaneous dysregulation of different downstream pathways. For example, the loss of Merlin activity triggers cell proliferation through Hippo, PI3K/Akt/mTOR, and FAK pathways. In that regard, targeting transduction pathways individually has been ineffective in abrogating the proliferative potential of cancer cells. These negative results highlight the necessity to better understand the MPM pathobiology. Accordingly, a substantial number of basic and translational research efforts, covering the comprehensive evaluation of cellular and molecular features and their interconnections and relationships with the tumor microenvironment, are already in progress. The primary aim is to identify new risk factors and novel therapeutic targets and treatment strategies in MPM, and integrative and high throughput genomics and functional genomics studies can definitely help advance these efforts.

Author Contributions: E.C. performed the literature search, prepared the figures and the tables, and wrote the manuscript. S.S. conceptualized the idea, contributed to the literature search, and wrote the manuscript. All authors have read and agreed to the published version of the manuscript.

Funding: This work was supported by the Scientific and Technological Research Council of Turkey (TUBITAK) via the project number $117 Z 227$. 
Acknowledgments: Serif Senturk is supported by the Young Scientists Award Program of the Turkish Academy of Sciences (TUBA GEBIP 2017) and the Science Academy's Young Scientist Awards Program (BAGEP 2019). Figures were created with BioRender.com. Ece Cakiroglu is a recipient of the TUBITAK BIDEB 2211-C fellowship. We thank Dilara Demirci and Bengisu Uluata Dayanc for the critical reading of the manuscript.

Conflicts of Interest: The authors declare no conflict of interest.

\section{Abbreviations}

2D

$3 \mathrm{D}$

Adeno-Cre

ALCAM

BAP1

BARD1

BNC

BRCA1

BUB1

cBioPortal

CD79B

CDK1

CDK7

CDKI

CDKN2A

CDKN2B

$\mathrm{CGH}$

CNA

COSMIC

c-Src

DDB1

DepMap

DRP1

dTMP

dUMP

ECM

EEF2

EGFR

EGFR-TKI

EIF3A

EIF3A

EMT

EPHB2

ERM

ER $\beta$

EZH2

FAK

FAT4

FDA

FGF

FGFRi

FLG

GEM

GEPIA

GPI

H3K27me3

HCF-1
Two dimensional

Three dimensional

Adenovirus expressing Cre recombinase

Activated leukocyte cell-adhesion molecule

BRCA1-associated protein 1

BRCA1-associated RING domain protein 1

BAP1, NF2, and CDKN2AB

Breast Cancer Type 1

BUB1 mitotic checkpoint serine/threonine-protein kinase

The cBio Cancer Genomics Portal

CD79b molecule

Cyclin dependent kinase 1

Cyclin-dependent kinase 7

Cyclin-dependent kinase inhibitors

Cyclin-dependent kinase inhibitor 2A

Cyclin-dependent kinase inhibitor 2B

Comparative genomic hybridization

Copy number alterations

Catalogue of Somatic Mutations in Cancer

SRC proto-oncogene, non-receptor tyrosine kinase

Damage specific DNA binding protein 1

The Cancer Dependency Map

Dynamin related protein

Deoxythymidine monophosphate

Deoxyuridine monophosphate

Extracellular matrix

Eukaryotic translation elongation factor 2

Epidermal growth factor receptor

EGFR tyrosine kinase inhibitor

Eukaryotic translation initiation factor 3 subunit A

Eukaryotic translation initiation factor 3 subunit A

Epithelial-mesenchymal transition

Ephrin B2 receptor

Ezrin, Radixin, and Moesin

Estrogen receptor beta

Enhancer of zeste homolog 2

Focal adhesion kinase

FAT Atypical Cadherin 4

Food and Drug Administration

Fibroblast growth factor

FGFR kinase inhibitor

Filaggrin

Genetically engineered mouse

Gene expression profiling interactive analysis

Glycosylphosphatidylinositol

H3 lysine methylation

Host cell factor 1 


\begin{tabular}{|c|c|}
\hline $\mathrm{HIF}-1 \alpha$ & Hypoxia-inducible factor $1 \alpha$ \\
\hline Hippo & Salvador-Warts-Hippo \\
\hline HSPE1 & Heat shock protein family E (Hsp10) member 1 \\
\hline ICGC & International Cancer Genome Consortium \\
\hline IGFBP & Insulin-like growth factor binding protein \\
\hline KIF & Kinesin family protein \\
\hline LATS2 & Large tumor suppressor kinase 2 \\
\hline $\operatorname{lncRNA}$ & Long non-coding RNA \\
\hline LP-WGS & Low-pass whole genome sequencing \\
\hline LRP4 & LDL Receptor Related Protein 4 \\
\hline MAD2L1 & Mitotic arrest deficient 2 like 1 \\
\hline MDM4 & MDM4 regulator of p53 \\
\hline Merlin & Moesin-ezrin-radixin-like protein \\
\hline MET & Mesenchymal-to-epithelial \\
\hline miRNA & MicroRNA \\
\hline MM & Mithramycin \\
\hline MMP & Matrix metalloprotease \\
\hline MPM & Malignant pleural mesothelioma \\
\hline MSAC & Mitotic spindle assembly checkpoint \\
\hline MSLN & Mesothelin \\
\hline mTORC1/2 & mTOR complex $1 / 2$ \\
\hline MYC & MYC proto-oncogene, bHLH transcription factor \\
\hline $\mathrm{NC}$ & NF2 and CDKN2AB \\
\hline NCI & National Cancer Institute \\
\hline ncRNA & Non-coding RNA \\
\hline NDC80 & Kinetochore complex component \\
\hline NF2 & Neurofibromatosis type 2 \\
\hline NGS & Next generation sequencing \\
\hline NHGRI & National Human Genome Research Institute \\
\hline PDGF & Platelet-derived growth factor \\
\hline PDX & Patient-derived xenograft \\
\hline PFS & Progression-free survival \\
\hline PI3K & Phosphoinositide 3-kinase \\
\hline PKC & Protein kinase C \\
\hline PLK1 & Polo like kinase 1 \\
\hline $\mathrm{pRb}$ & Retinoblastoma protein \\
\hline PRC2 & Polycomb repressive complex 2 \\
\hline PTCH1 & Patched 1 \\
\hline RAN & RAN, member RAS oncogene family \\
\hline RNAi & RNA interference \\
\hline RNR & Ribonucleotide reductase \\
\hline RPS15A & Ribosomal protein S15a \\
\hline RPTOR & Regulatory associated protein of mTOR complex 1 \\
\hline RRM1 & Ribonucleotide reductase catalytic subunit M1 \\
\hline RRM2 & Ribonucleotide reductase catalytic subunit M2 \\
\hline RSTK & Receptor serine/threonine kinase \\
\hline RTK & Receptor tyrosine kinase \\
\hline RUVBL1 & RuvB like AAA ATPase 1 \\
\hline SETD2 & SET domain containing 2 \\
\hline SFK & Src Family Kinase \\
\hline SMRP & Soluble mesothelin-related peptides \\
\hline SNRNP & Small nuclear ribonucleoprotein \\
\hline SNRPD1 & Small nuclear ribonucleoprotein D1 polypeptide \\
\hline
\end{tabular}




$\begin{array}{ll}\text { SP1 } & \text { Sp1 transcription factor } \\ \text { SUZ12 } & \text { SUZ12 polycomb repressive complex 2 subunit } \\ \text { TCGA } & \text { The Cancer Genome Atlas } \\ \text { TERT } & \text { Telomerase reverse rranscriptase } \\ \text { TF } & \text { Transcription factor } \\ \text { TGF- } \beta & \text { Transforming growth factor } \beta \\ \text { TP53 } & \text { Tumor Protein P53 } \\ \text { TS } & \text { Thymidylate synthase } \\ \text { TTN } & \text { Titin } \\ \text { UBA1 } & \text { Ubiquitin like modifier activating enzyme 1 } \\ \text { UCH } & \text { Ubiquitin carboxy-terminal hydrolase } \\ \text { VCP } & \text { Valosin containing protein } \\ \text { VEGF } & \text { Vascular endothelial growth factor } \\ \text { WT1 } & \text { Wilms Tumor Protein 1 } \\ \text { YAP1 } & \text { Yes-associated protein } \\ \text { ZEB1 } & \text { Zinc finger e-box binding homeobox 1 }\end{array}$

\section{References}

1. Yap, T.A.; Aerts, J.G.; Popat, S.; Fennell, D.A. Novel insights into mesothelioma biology and implications for therapy. Nat. Rev. Cancer 2017, 17, 475-488. [CrossRef]

2. Bray, F.; Ferlay, J.; Soerjomataram, I.; Siegel, R.L.; Torre, L.A.; Jemal, A. Global cancer statistics 2018: GLOBOCAN estimates of incidence and mortality worldwide for 36 cancers in 185 countries. CA Cancer J. Clin. 2018, 68, 394-424. [CrossRef]

3. Beebe-Dimmer, J.L.; Fryzek, J.P.; Yee, C.L.; Dalvi, T.B.; Garabrant, D.H.; Schwartz, A.G.; Gadgeel, S. Mesothelioma in the United States: A Surveillance, Epidemiology, and End Results (SEER)-Medicare investigation of treatment patterns and overall survival. Clin. Epidemiol. 2016, 8, 743-750. [CrossRef]

4. Baas, P.; Fennell, D.; Kerr, K.M.; Van Schil, P.E.; Haas, R.L.; Peters, S. Malignant pleural mesothelioma: ESMO Clinical Practice Guidelines for diagnosis, treatment and follow-up. Ann. Oncol. 2015, 26, v31-v39. [CrossRef]

5. Cinausero, M.; Rihawi, K.; Cortiula, F.; Follador, A.; Fasola, G.; Ardizzoni, A. Emerging therapies in malignant pleural mesothelioma. Crit. Rev. Oncol. Hematol. 2019, 144, 102815. [CrossRef] [PubMed]

6. Tsao, A.S.; Wistuba, I.; Roth, J.A.; Kindler, H.L. Malignant pleural mesothelioma. J. Clin. Oncol. 2009, 27, 2081-2090. [CrossRef] [PubMed]

7. Roushdy-Hammady, I.; Siegel, J.; Emri, S.; Testa, J.R.; Carbone, M. Genetic-susceptibility factor and malignant mesothelioma in the Cappadocian region of Turkey. Lancet 2001, 357, 444-445. [CrossRef]

8. Dogan, A.U.; Baris, Y.I.; Dogan, M.; Emri, S.; Steele, I.; Elmishad, A.G.; Carbone, M. Genetic predisposition to fiber carcinogenesis causes a mesothelioma epidemic in Turkey. Cancer Res. 2006, 66, 5063-5068. [CrossRef] [PubMed]

9. Testa, J.R.; Cheung, M.; Pei, J.; Below, J.E.; Tan, Y.; Sementino, E.; Cox, N.J.; Dogan, A.U.; Pass, H.I.; Trusa, S.; et al. Germline BAP1 mutations predispose to malignant mesothelioma. Nat. Genet. 2011, 43, 1022-1025. [CrossRef]

10. Carbone, M.; Adusumilli, P.S.; Alexander, H.R.; Baas, P.; Bardelli, F.; Bononi, A.; Bueno, R.; Felley-Bosco, E.; Galateau-Salle, F.; Jablons, D.; et al. Mesothelioma: Scientific clues for prevention, diagnosis, and therapy. CA Cancer J. Clin. 2019, 69, 402-429. [CrossRef]

11. Blyth, K.G.; Murphy, D.J. Progress and challenges in Mesothelioma: From bench to bedside. Respir. Med. 2018, 134, 31-41. [CrossRef] [PubMed]

12. Ahmadzada, T.; Reid, G.; Kao, S. Biomarkers in malignant pleural mesothelioma: Current status and future directions. J. Thorac. Dis. 2018, 10, S1003-S1007. [CrossRef] [PubMed]

13. Scherpereel, A.; Wallyn, F.; Albelda, S.M.; Munck, C. Novel therapies for malignant pleural mesothelioma. Lancet Oncol. 2018, 19, e161-e172. [CrossRef]

14. Takuwa, T.; Hasegawa, S. Current surgical strategies for malignant pleural mesothelioma. Surg. Today 2016, 46, 887-894. [CrossRef] 
15. Bronte, G.; Incorvaia, L.; Rizzo, S.; Passiglia, F.; Galvano, A.; Rizzo, F.; Rolfo, C.; Fanale, D.; Listì, A.; Natoli, C.; et al. The resistance related to targeted therapy in malignant pleural mesothelioma: Why has not the target been hit yet? Crit. Rev. Oncol. Hematol. 2016, 107, 20-32. [CrossRef]

16. Thurneysen, C.; Opitz, I.; Kurtz, S.; Weder, W.; Stahel, R.A.; Felley-Bosco, E. Functional inactivation of NF2/merlin in human mesothelioma. Lung Cancer 2009, 64, 140-147. [CrossRef] [PubMed]

17. Illei, P.B.; Rusch, V.W.; Zakowski, M.F.; Ladanyi, M. Homozygous deletion of CDKN2A and codeletion of the methylthioadenosine phosphorylase gene in the majority of pleural mesotheliomas. Clin. Cancer Res. 2003, 9, 2108-2113.

18. Bott, M.; Brevet, M.; Taylor, B.S.; Shimizu, S.; Ito, T.; Wang, L.; Creaney, J.; Lake, R.A.; Zakowski, M.F.; Reva, B.; et al. The nuclear deubiquitinase BAP1 is commonly inactivated by somatic mutations and 3p21.1 losses in malignant pleural mesothelioma. Nat. Genet. 2011, 43, 668-672. [CrossRef]

19. De Reyniès, A.; Jaurand, M.-C.; Renier, A.; Couchy, G.; Hysi, I.; Elarouci, N.; Galateau-Sallé, F.; Copin, M.-C.; Hofman, P.; Cazes, A.; et al. Molecular classification of malignant pleural mesothelioma: Identification of a poor prognosis subgroup linked to the epithelial-to-mesenchymal transition. Clin. Cancer Res. 2014, 20, 1323-1334. [CrossRef]

20. Lindholm, P.M.; Salmenkivi, K.; Vauhkonen, H.; Nicholson, A.G.; Anttila, S.; Kinnula, V.L.; Knuutila, S. Gene copy number analysis in malignant pleural mesothelioma using oligonucleotide array CGH. Cytogenet. Genome Res. 2007, 119, 46-52. [CrossRef]

21. Jean, D.; Daubriac, J.; Le Pimpec-Barthes, F.; Galateau-Salle, F.; Jaurand, M.-C. molecular changes in mesothelioma with an impact on prognosis and treatment. Arch. Pathol. Lab. Med. 2012, 136, 277-293. [CrossRef] [PubMed]

22. The Cancer Genome Atlas Program-National Cancer Institute. Available online: https://www.cancer.gov/ about-nci/organization/ccg/research/structural-genomics/tcga (accessed on 22 July 2020).

23. Bueno, R.; Stawiski, E.W.; Goldstein, L.D.; Durinck, S.; De Rienzo, A.; Modrusan, Z.; Gnad, F.; Nguyen, T.T.; Jaiswal, B.S.; Chirieac, L.R.; et al. Comprehensive genomic analysis of malignant pleural mesothelioma identifies recurrent mutations, gene fusions and splicing alterations. Nat. Genet. 2016, 48, 407-416. [CrossRef] [PubMed]

24. Borczuk, A.C.; Pei, J.; Taub, R.N.; Levy, B.; Nahum, O.; Chen, J.; Chen, K.; Testa, J.R. Genome-wide analysis of abdominal and pleural malignant mesothelioma with DNA arrays reveals both common and distinct regions of copy number alteration. Cancer Biol. Therapy 2016, 17, 328-335. [CrossRef] [PubMed]

25. Guo, G.; Chmielecki, J.; Goparaju, C.; Heguy, A.; Dolgalev, I.; Carbone, M.; Seepo, S.; Meyerson, M.; Pass, H.I. Whole-exome sequencing reveals frequent genetic alterations in BAP1, NF2, CDKN2A, and CUL1 in malignant pleural mesothelioma. Cancer Res. 2015, 75, 264-269. [CrossRef] [PubMed]

26. Nasu, M.; Emi, M.; Pastorino, S.; Tanji, M.; Powers, A.; Luk, H.; Baumann, F.; Zhang, Y.-A.; Gazdar, A.; Kanodia, S.; et al. High incidence of somatic BAP1 alterations in sporadic malignant mesothelioma. J. Thorac. Oncol. 2015, 10, 565-576. [CrossRef]

27. Harbour, J.W.; Onken, M.D.; Roberson, E.D.O.; Duan, S.; Cao, L.; Worley, L.A.; Council, M.L.; Matatall, K.A.; Helms, C.; Bowcock, A.M. Frequent mutation of BAP1 in metastasizing uveal melanomas. Science 2010, 330, 1410-1413. [CrossRef]

28. Zhang, N.; Chen, S.; Jiang, G.; Wu, Y.; Shao, J.; Liu, W.; Wang, X.; Na, R.; Xu, J. The study on copy number alteration of clear cell renal cancer in Chinese population. J. Cancer 2020, 11, 16-24. [CrossRef]

29. Eletr, Z.M.; Wilkinson, K.D. Regulation of proteolysis by human deubiquitinating enzymes. Biochim. Biophys. Acta-Mol. Cell Res. 2014, 1843, 114-128. [CrossRef]

30. Eletr, Z.M.; Wilkinson, K.D. An Emerging model for BAP1's role in regulating cell cycle progression. Cell. Biochem. Biophys. 2011, 60, 3-11. [CrossRef]

31. Bononi, A.; Giorgi, C.; Patergnani, S.; Larson, D.; Verbruggen, K.; Tanji, M.; Pellegrini, L.; Signorato, V.; Olivetto, F.; Pastorino, S.; et al. BAP1 regulates IP3R3-mediated Ca2+ flux to mitochondria suppressing cell transformation. Nature 2017, 546, 549-553. [CrossRef]

32. Carbone, M.; Harbour, J.W.; Brugarolas, J.; Bononi, A.; Pagano, I.; Dey, A.; Krausz, T.; Pass, H.I.; Yang, H.; Gaudino, G. Biological mechanisms and clinical significance of BAP1 mutations in human cancer. Cancer Discov. 2020, 10, 1103-1120. [CrossRef] [PubMed] 
33. Chen, P.; Wang, H.; Zhang, W.; Chen, Y.; Lv, Y.; Wu, D.; Guo, M.; Deng, H. Loss of BAP1 Results in growth inhibition and enhances mesenchymal-epithelial transition in kidney tumor cells. Mol. Cell. Proteom. 2019, 18, 1320-1329. [CrossRef] [PubMed]

34. Affar, E.B.; Carbone, M. BAP1 regulates different mechanisms of cell death. Cell Death Dis. 2018, 9, 1151. [CrossRef] [PubMed]

35. Bononi, A.; Yang, H.; Giorgi, C.; Patergnani, S.; Pellegrini, L.; Su, M.; Xie, G.; Signorato, V.; Pastorino, S.; Morris, P.; et al. Germline BAP1 mutations induce a Warburg effect. Cell Death Differ. 2017, 24, 1694-1704. [CrossRef] [PubMed]

36. Zhang, Y.; Shi, J.; Liu, X.; Feng, L.; Gong, Z.; Koppula, P.; Sirohi, K.; Li, X.; Wei, Y.; Lee, H.; et al. BAP1 links metabolic regulation of ferroptosis to tumour suppression. Nat. Cell Biol. 2018, 20, 1181-1192. [CrossRef]

37. Christou, C.; Kyriacou, K. BRCA1 and its network of interacting partners. Biology 2013, 2, 40-63. [CrossRef]

38. Rai, K.; Pilarski, R.; Boru, G.; Rehman, M.; Saqr, A.H.; Massengill, J.B.; Singh, A.; Marino, M.J.; Davidorf, F.H.; Cebulla, C.M.; et al. Germline BAP1 alterations in familial uveal melanoma: BAP1 in familial uveal melanoma. Genes Chromosomes Cancer 2017, 56, 168-174. [CrossRef]

39. Njauw, C.-N.J.; Kim, I.; Piris, A.; Gabree, M.; Taylor, M.; Lane, A.M.; DeAngelis, M.M.; Gragoudas, E.; Duncan, L.M.; Tsao, H. Germline BAP1 inactivation is preferentially associated with metastatic ocular melanoma and cutaneous-ocular melanoma families. PLoS ONE 2012, 7, e35295. [CrossRef]

40. Carbone, M.; Ferris, L.K.; Baumann, F.; Napolitano, A.; Lum, C.A.; Flores, E.G.; Gaudino, G.; Powers, A.; Bryant-Greenwood, P.; Krausz, T.; et al. BAP1 cancer syndrome: Malignant mesothelioma, uveal and cutaneous melanoma, and MBAITs. J. Transl. Med. 2012, 10, 179. [CrossRef]

41. Carbone, M.; Emri, S.; Dogan, A.U.; Steele, I.; Tuncer, M.; Pass, H.I.; Baris, Y.I. A mesothelioma epidemic in Cappadocia: Scientific developments and unexpected social outcomes. Nat. Rev. Cancer 2007, 7, 147-154. [CrossRef]

42. Haugh, A.M.; Njauw, C.-N.; Bubley, J.A.; Verzì, A.E.; Zhang, B.; Kudalkar, E.; VandenBoom, T.; Walton, K.; Swick, B.L.; Kumar, R.; et al. Genotypic and phenotypic features of BAP1 cancer syndrome: A report of 8 new families and review of cases in the literature. JAMA Dermatol. 2017, 153, 999-1006. [CrossRef] [PubMed]

43. Pastorino, S.; Yoshikawa, Y.; Pass, H.I.; Emi, M.; Nasu, M.; Pagano, I.; Takinishi, Y.; Yamamoto, R.; Minaai, M.; Hashimoto-Tamaoki, T.; et al. A subset of mesotheliomas with improved survival occurring in carriers of BAP1 and other germline mutations. J. Clin. Oncol. 2018. [CrossRef] [PubMed]

44. Panou, V.; Gadiraju, M.; Wolin, A.; Weipert, C.M.; Skarda, E.; Husain, A.N.; Patel, J.D.; Rose, B.; Zhang, S.R.; Weatherly, M.; et al. Frequency of germline mutations in cancer susceptibility genes in malignant mesothelioma. J. Clin. Oncol. 2018, 36, 2863-2871. [CrossRef] [PubMed]

45. Hassan, R.; Morrow, B.; Thomas, A.; Walsh, T.; Lee, M.K.; Gulsuner, S.; Gadiraju, M.; Panou, V.; Gao, S.; Mian, I.; et al. Inherited predisposition to malignant mesothelioma and overall survival following platinum chemotherapy. Proc. Natl. Acad. Sci. USA 2019, 116, 9008-9013. [CrossRef]

46. Panou, V.; Roe, O.D. Inherited genetic mutations and polymorphisms in malignant mesothelioma: A comprehensive review. Int. J. Mol. Sci. 2020, 21, 4327. [CrossRef]

47. Sherr, C.J. Divorcing ARF and p53: An unsettled case. Nat. Rev. Cancer 2006, 6, 663-673. [CrossRef]

48. Knudsen, E.S.; Witkiewicz, A.K. The Strange case of CDK4/6 inhibitors: Mechanisms, resistance, and combination strategies. Trends Cancer 2017, 3, 39-55. [CrossRef]

49. Sobhani, N.; Corona, S.P.; Zanconati, F.; Generali, D. Cyclin dependent kinase 4 and 6 inhibitors as novel therapeutic agents for targeted treatment of malignant mesothelioma. Genes Cancer 2017, 8, 495-496. [CrossRef]

50. Bonelli, M.A.; Digiacomo, G.; Fumarola, C.; Alfieri, R.; Quaini, F.; Falco, A.; Madeddu, D.; La Monica, S.; Cretella, D.; Ravelli, A.; et al. Combined inhibition of CDK4/6 and PI3K/AKT/mTOR pathways induces a synergistic anti-tumor effect in malignant pleural mesothelioma cells. Neoplasia 2017, 19, 637-648. [CrossRef]

51. Facchetti, G.; Petrella, F.; Spaggiari, L.; Rimoldi, I. Malignant pleural mesothelioma: State of the art and advanced cell therapy. Eur. J. Med. Chem. 2017, 142, 266-270. [CrossRef]

52. Sekido, Y.; Pass, H.I.; Bader, S.; Mew, D.J.; Christman, M.F.; Gazdar, A.F.; Minna, J.D. Neurofibromatosis type 2 (NF2) gene is somatically mutated in mesothelioma but not in lung cancer. Cancer Res. 1995, 55, 1227-1231. [PubMed]

53. Sato, T.; Sekido, Y. NF2/Merlin Inactivation and potential therapeutic targets in mesothelioma. Int. J. Mol. Sci. 2018, 19, 988. [CrossRef] [PubMed] 
54. Coy, S.; Rashid, R.; Stemmer-Rachamimov, A.; Santagata, S. An update on the CNS manifestations of neurofibromatosis type 2. Acta Neuropathol. 2020, 139, 643-665. [CrossRef] [PubMed]

55. Stamenkovic, I.; Yu, Q. Merlin, a "magic" linker between extracellular cues and intracellular signaling pathways that regulate cell motility, proliferation, and survival. Curr. Protein Pept. Sci. 2010, 11, 471-484. [CrossRef]

56. Li, W.; Cooper, J.; Karajannis, M.A.; Giancotti, F.G. Merlin: A tumour suppressor with functions at the cell cortex and in the nucleus. EMBO Rep. 2012. [CrossRef] [PubMed]

57. Poulikakos, P.I.; Xiao, G.-H.; Gallagher, R.; Jablonski, S.; Jhanwar, S.C.; Testa, J.R. Re-expression of the tumor suppressor NF2/merlin inhibits invasiveness in mesothelioma cells and negatively regulates FAK. Oncogene 2006, 25, 5960-5968. [CrossRef]

58. Shapiro, I.M.; Kolev, V.N.; Vidal, C.M.; Kadariya, Y.; Ring, J.E.; Wright, Q.; Weaver, D.T.; Menges, C.; Padval, M.; McClatchey, A.I.; et al. Merlin deficiency predicts fak inhibitor sensitivity: A synthetic lethal relationship. Sci. Transl. Med. 2014, 6, 237ra68. [CrossRef]

59. Lo Iacono, M.; Monica, V.; Righi, L.; Grosso, F.; Libener, R.; Vatrano, S.; Bironzo, P.; Novello, S.; Musmeci, L.; Volante, M.; et al. Targeted next-generation sequencing of cancer genes in advanced stage malignant pleural mesothelioma: A retrospective study. J. Thorac. Oncol. 2015, 10, 492-499. [CrossRef]

60. De Rienzo, A.; Archer, M.A.; Yeap, B.Y.; Dao, N.; Sciaranghella, D.; Sideris, A.C.; Zheng, Y.; Holman, A.G.; Wang, Y.E.; Dal Cin, P.S.; et al. Gender-specific molecular and clinical features underlie malignant pleural mesothelioma. Cancer Res. 2016, 76, 319-328. [CrossRef]

61. Sneddon, S.; Dick, I.; Lee, Y.C.G.; Bill Musk, A.W.; Patch, A.-M.; Pearson, J.V.; Waddell, N.; Allcock, R.J.N.; Holt, R.A.; Robinson, B.W.S.; et al. Malignant cells from pleural fluids in malignant mesothelioma patients reveal novel mutations. Lung Cancer 2018, 119, 64-70. [CrossRef]

62. Hmeljak, J.; Sanchez-Vega, F.; Hoadley, K.A.; Shih, J.; Stewart, C.; Heiman, D.; Tarpey, P.; Danilova, L.; Drill, E.; Gibb, E.A.; et al. Integrative molecular characterization of malignant pleural mesothelioma. Cancer Discov. 2018, 8, 1548-1565. [CrossRef] [PubMed]

63. Tranchant, R.; Quetel, L.; Tallet, A.; Meiller, C.; Renier, A.; de Koning, L.; de Reynies, A.; Le Pimpec-Barthes, F.; Zucman-Rossi, J.; Jaurand, M.-C.; et al. Co-occurring Mutations of Tumor Suppressor Genes, LATS2 and NF2, in Malignant Pleural Mesothelioma. Clin. Cancer Res. 2017, 23, 3191-3202. [CrossRef] [PubMed]

64. Mizuno, T.; Murakami, H.; Fujii, M.; Ishiguro, F.; Tanaka, I.; Kondo, Y.; Akatsuka, S.; Toyokuni, S.; Yokoi, K.; Osada, H.; et al. YAP induces malignant mesothelioma cell proliferation by upregulating transcription of cell cycle-promoting genes. Oncogene 2012, 31, 5117-5122. [CrossRef] [PubMed]

65. Hylebos, M.; Van Camp, G.; Vandeweyer, G.; Fransen, E.; Beyens, M.; Cornelissen, R.; Suls, A.; Pauwels, P.; van Meerbeeck, J.P.; Op de Beeck, K. Large-scale copy number analysis reveals variations in genes not previously associated with malignant pleural mesothelioma. Oncotarget 2017, 8, 113673-113686. [CrossRef]

66. Edmunds, J.W.; Mahadevan, L.C.; Clayton, A.L. Dynamic histone H3 methylation during gene induction: HYPB/Setd2 mediates all H3K36 trimethylation. EMBO J. 2008, 27, 406-420. [CrossRef]

67. Park, I.Y.; Powell, R.T.; Tripathi, D.N.; Dere, R.; Ho, T.H.; Blasius, T.L.; Chiang, Y.-C.; Davis, I.J.; Fahey, C.C.; Hacker, K.E.; et al. Dual Chromatin and Cytoskeletal Remodeling by SETD2. Cell 2016, 166, 950-962. [CrossRef]

68. Vinagre, J.; Almeida, A.; Pópulo, H.; Batista, R.; Lyra, J.; Pinto, V.; Coelho, R.; Celestino, R.; Prazeres, H.; Lima, L.; et al. Frequency of TERT promoter mutations in human cancers. Nat. Commun. 2013, 4, 2185. [CrossRef]

69. Tallet, A.; Nault, J.-C.; Renier, A.; Hysi, I.; Galateau-Sallé, F.; Cazes, A.; Copin, M.-C.; Hofman, P.; Andujar, P.; Le Pimpec-Barthes, F; et al. Overexpression and promoter mutation of the TERT gene in malignant pleural mesothelioma. Oncogene 2014, 33, 3748-3752. [CrossRef]

70. Quetel, L.; Meiller, C.; Assié, J.; Blum, Y.; Imbeaud, S.; Montagne, F.; Tranchant, R.; Wolf, J.; Caruso, S.; Copin, M.; et al. Genetic alterations of malignant pleural mesothelioma: Association with tumor heterogeneity and overall survival. Mol. Oncol. 2020, 14, 1207-1223. [CrossRef]

71. Kato, S.; Tomson, B.N.; Buys, T.P.H.; Elkin, S.K.; Carter, J.L.; Kurzrock, R. Genomic landscape of malignant mesotheliomas. Mol. Cancer Ther. 2016, 15, 2498-2507. [CrossRef]

72. Sneddon, S.; Patch, A.-M.; Dick, I.M.; Kazakoff, S.; Pearson, J.V.; Waddell, N.; Allcock, R.J.N.; Holt, R.A.; Robinson, B.W.S.; Creaney, J. Whole exome sequencing of an asbestos-induced wild-type murine model of malignant mesothelioma. BMC Cancer 2017, 17, 396. [CrossRef] [PubMed] 
73. Tate, J.G.; Bamford, S.; Jubb, H.C.; Sondka, Z.; Beare, D.M.; Bindal, N.; Boutselakis, H.; Cole, C.G.; Creatore, C.; Dawson, E.; et al. COSMIC: The catalogue of somatic mutations in cancer. Nucl. Acids Res. 2019, 47, D941-D947. [CrossRef] [PubMed]

74. Zhang, J.; Bajari, R.; Andric, D.; Gerthoffert, F.; Lepsa, A.; Nahal-Bose, H.; Stein, L.D.; Ferretti, V. The International cancer genome consortium data portal. Nat. Biotechnol. 2019, 37, 367-369. [CrossRef] [PubMed]

75. ICGC/TCGA. Pan-cancer analysis of whole genomes consortium pan-cancer analysis of whole genomes. Nature 2020, 578, 82-93. [CrossRef]

76. Mäki-Nevala, S.; Sarhadi, V.K.; Knuuttila, A.; Scheinin, I.; Ellonen, P.; Lagström, S.; Rönty, M.; Kettunen, E.; Husgafvel-Pursiainen, K.; Wolff, H.; et al. Driver gene and novel mutations in asbestos-exposed lung adenocarcinoma and malignant mesothelioma detected by exome sequencing. Lung 2016, 194, 125-135. [CrossRef]

77. Ugurluer, G.; Chang, K.; Gamez, M.E.; Arnett, A.L.; Jayakrishnan, R.; Miller, R.C.; Sio, T.T. Genome-based mutational analysis by next generation sequencing in patients with malignant pleural and peritoneal mesothelioma. Anticancer Res. 2016, 36, 2331-2338. [CrossRef]

78. Imielinski, M.; Berger, A.H.; Hammerman, P.S.; Hernandez, B.; Pugh, T.J.; Hodis, E.; Cho, J.; Suh, J.; Capelletti, M.; Sivachenko, A.; et al. Mapping the hallmarks of lung adenocarcinoma with massively parallel sequencing. Cell 2012, 150, 1107-1120. [CrossRef]

79. Ding, L.; Getz, G.; Wheeler, D.A.; Mardis, E.R.; McLellan, M.D.; Cibulskis, K.; Sougnez, C.; Greulich, H.; Muzny, D.M.; Morgan, M.B.; et al. Somatic mutations affect key pathways in lung adenocarcinoma. Nature 2008, 455, 1069-1075. [CrossRef]

80. Uruga, H.; Fujii, T.; Nakamura, N.; Moriguchi, S.; Kishi, K.; Takaya, H. Squamous cell transformation as a mechanism of acquired resistance to tyrosine kinase inhibitor in EGFR-mutated lung adenocarcinoma: A report of two cases. Respirol. Case Rep. 2020, 8. [CrossRef]

81. Huang, D.; Sun, W.; Zhou, Y.; Li, P.; Chen, F.; Chen, H.; Xia, D.; Xu, E.; Lai, M.; Wu, Y.; et al. Mutations of key driver genes in colorectal cancer progression and metastasis. Cancer Metastasis Rev. 2018, 37, $173-187$. [CrossRef]

82. Zimmer, K.; Puccini, A.; Xiu, J.; Baca, Y.; Spizzo, G.; Lenz, H.-J.; Battaglin, F.; Goldberg, R.M.; Grothey, A.; Shields, A.F.; et al. WRN-mutated colorectal cancer is characterized by a distinct genetic phenotype. Cancers 2020, 12, 1319. [CrossRef] [PubMed]

83. Mathot, L.; Kundu, S.; Ljungström, V.; Svedlund, J.; Moens, L.; Adlerteg, T.; Falk-Sörqvist, E.; Rendo, V.; Bellomo, C.; Mayrhofer, M.; et al. Somatic ephrin receptor mutations are associated with metastasis in primary colorectal cancer. Cancer Res. 2017, 77, 1730-1740. [CrossRef]

84. Kim, J.E.; Kim, K.K.; Kim, S.Y.; Lee, J.; Park, S.H.; Park, J.O.; Park, Y.S.; Lim, H.Y.; Kang, W.K.; Kim, S.T. MAP2K1 mutation in colorectal cancer patients: Therapeutic challenge using patient-derived tumor cell lines. J. Cancer 2017, 8, 2263-2268. [CrossRef] [PubMed]

85. Shiovitz, S.; Korde, L.A. Genetics of breast cancer: A topic in evolution. Ann. Oncol. 2015, 26, 1291-1299. [CrossRef] [PubMed]

86. Cerami, E.; Gao, J.; Dogrusoz, U.; Gross, B.E.; Sumer, S.O.; Aksoy, B.A.; Jacobsen, A.; Byrne, C.J.; Heuer, M.L.; Larsson, E.; et al. The cBio cancer genomics Portal: An open platform for exploring multidimensional cancer genomics data: Figure 1. Cancer Discov. 2012, 2, 401-404. [CrossRef]

87. Gao, J.; Aksoy, B.A.; Dogrusoz, U.; Dresdner, G.; Gross, B.; Sumer, S.O.; Sun, Y.; Jacobsen, A.; Sinha, R.; Larsson, E.; et al. Integrative analysis of complex cancer genomics and clinical profiles using the cBioPortal. Sci. Sign. 2013, 6, pl1. [CrossRef]

88. Gordon, G.J.; Rockwell, G.N.; Jensen, R.V.; Rheinwald, J.G.; Glickman, J.N.; Aronson, J.P.; Pottorf, B.J.; Nitz, M.D.; Richards, W.G.; Sugarbaker, D.J.; et al. Identification of novel candidate oncogenes and tumor suppressors in malignant pleural mesothelioma using large-scale transcriptional profiling. Am. J. Pathol. 2005, 166, 1827-1840. [CrossRef]

89. Zhou, S.; Liu, L.; Li, H.; Eilers, G.; Kuang, Y.; Shi, S.; Yan, Z.; Li, X.; Corson, J.M.; Meng, F.; et al. Multipoint targeting of the PI3K/mTOR pathway in mesothelioma. Br. J. Cancer 2014, 110, 2479-2488. [CrossRef] 
90. El-Hosainy, A.; Hosny, H.; Gabal, S.; Ahmed, S.; El-Hinnawy, Y. Role of epidermal growth factor receptor in malignant pleural mesothelioma and its value for successful chemical pleurodesis. Egypt. J. Chest Dis. Tuberc. 2014, 63, 873-881. [CrossRef]

91. Suzuki, Y.; Murakami, H.; Kawaguchi, K.; Tanigushi, T.; Fujii, M.; Shinjo, K.; Kondo, Y.; Osada, H.; Shimokata, K.; Horio, Y.; et al. Activation of the PI3K-AKT pathway in human malignant mesothelioma cells. Mol. Med. Rep. 2009, 2, 181-188. [CrossRef]

92. Cedrés, S.; Montero, M.A.; Martinez, P.; Martinez, A.; Rodríguez-Freixinós, V.; Torrejon, D.; Gabaldon, A.; Salcedo, M.; Ramon Y Cajal, S.; Felip, E. Exploratory analysis of activation of PTEN-PI3K pathway and downstream proteins in malignant pleural mesothelioma (MPM). Lung Cancer 2012, 77, 192-198. [CrossRef] [PubMed]

93. Agarwal, V.; Campbell, A.; Beaumont, K.L.; Cawkwell, L.; Lind, M.J. PTEN protein expression in malignant pleural mesothelioma. Tumour Biol. 2013, 34, 847-851. [CrossRef] [PubMed]

94. Ou, W.-B.; Hubert, C.; Corson, J.M.; Bueno, R.; Flynn, D.L.; Sugarbaker, D.J.; Fletcher, J.A. Targeted inhibition of multiple receptor tyrosine kinases in mesothelioma. Neoplasia 2011, 13, 12-22. [CrossRef] [PubMed]

95. Vintman, L.; Nielsen, S.; Berner, A.; Reich, R.; Davidson, B. Mitogen-activated protein kinase expression and activation does not differentiate benign from malignant mesothelial cells. Cancer 2005, 103, 2427-2433. [CrossRef]

96. Dazzi, H.; Hasleton, P.S.; Thatcher, N.; Wilkes, S.; Swindell, R.; Chatterjee, A.K. Malignant pleural mesothelioma and epidermal growth factor receptor (EGF-R). Relationship of EGF-R with histology and survival using fixed paraffin embedded tissue and the F4, monoclonal antibody. Br. J. Cancer 1990, 61, 924-926. [CrossRef]

97. Mezzapelle, R.; Miglio, U.; Rena, O.; Paganotti, A.; Allegrini, S.; Antona, J.; Molinari, F.; Frattini, M.; Monga, G.; Alabiso, O.; et al. Mutation analysis of the EGFR gene and downstream signalling pathway in histologic samples of malignant pleural mesothelioma. Br. J. Cancer 2013, 108, 1743-1749. [CrossRef]

98. Pasello, G.; Favaretto, A. Molecular targets in malignant pleural mesothelioma treatment. Curr. Drug Targets 2009, 10, 1235-1244. [CrossRef]

99. Govindan, R.; Kratzke, R.A.; Herndon, J.E.; Niehans, G.A.; Vollmer, R.; Watson, D.; Green, M.R.; Kindler, H.L. Cancer and leukemia group B (CALGB 30101) gefitinib in patients with malignant mesothelioma: A phase II study by the cancer and leukemia group B. Clin. Cancer Res. 2005, 11, 2300-2304. [CrossRef]

100. Garland, L.L.; Rankin, C.; Gandara, D.R.; Rivkin, S.E.; Scott, K.M.; Nagle, R.B.; Klein-Szanto, A.J.P.; Testa, J.R.; Altomare, D.A.; Borden, E.C. Phase II study of erlotinib in patients with malignant pleural mesothelioma: A Southwest Oncology Group Study. J. Clin. Oncol. 2007, 25, 2406-2413. [CrossRef]

101. Hanahan, D.; Weinberg, R.A. Hallmarks of cancer: The next generation. Cell 2011, 144, 646-674. [CrossRef]

102. Edwards, J.G.; Cox, G.; Andi, A.; Jones, J.L.; Walker, R.A.; Waller, D.A.; O’Byrne, K.J. Angiogenesis is an independent prognostic factor in malignant mesothelioma. Br. J. Cancer 2001, 85, 863-868. [CrossRef] [PubMed]

103. Zalcman, G.; Mazieres, J.; Margery, J.; Greillier, L.; Audigier-Valette, C.; Moro-Sibilot, D.; Molinier, O.; Corre, R.; Monnet, I.; Gounant, V.; et al. Bevacizumab for newly diagnosed pleural mesothelioma in the Mesothelioma Avastin Cisplatin Pemetrexed Study (MAPS): A randomised, controlled, open-label, phase 3 trial. Lancet 2016, 387, 1405-1414. [CrossRef]

104. Klabatsa, A.; Sheaff, M.T.; Steele, J.P.C.; Evans, M.T.; Rudd, R.M.; Fennell, D.A. Expression and prognostic significance of hypoxia-inducible factor 1alpha (HIF-1alpha) in malignant pleural mesothelioma (MPM). Lung Cancer 2006, 51, 53-59. [CrossRef]

105. Nowak, A.K.; Brosseau, S.; Cook, A.; Zalcman, G. Antiangiogeneic strategies in Mesothelioma. Front. Oncol. 2020, 10, 126. [CrossRef] [PubMed]

106. Salgia, R.; Loganathan, S.; Kanteti, R.; Siddiqui, S.; El-Hashani, E.; Tretiakova, M.; Vigneswaran, H.; Cervantes, G.; Natarajan, V.; Husain, A.; et al. Role of protein kinase C $\beta$ and vascular endothelial growth factor receptor in malignant pleural mesothelioma: Therapeutic implications and the usefulness of Caenorhabditis elegans model organism. J. Carcinog. 2011, 10, 4. [CrossRef]

107. Albonici, L.; Palumbo, C.; Manzari, V. Role of inflammation and angiogenic growth factors in malignant mesothelioma. In Malignant Mesothelioma; Belli, C., Ed.; InTech: London, UK, 2012; ISBN 978-953-51-0901-3.

108. Saunders, W.S.; Hoyt, M.A. Kinesin-related proteins required for structural integrity of the mitotic spindle. Cell 1992, 70, 451-458. [CrossRef] 
109. Musacchio, A. The molecular biology of spindle assembly checkpoint signaling dynamics. Curr. Biol. 2015, 25, R1002-R1018. [CrossRef]

110. Lamothe, R.; Costantino, L.; Koshland, D.E. The spatial regulation of condensin activity in chromosome condensation. Genes Dev. 2020, 34, 819-831. [CrossRef]

111. Clute, P.; Pines, J. Temporal and spatial control of cyclin B1 destruction in metaphase. Nat. Cell Biol. 1999, 1, 82-87. [CrossRef]

112. Crispi, S.; Calogero, R.A.; Santini, M.; Mellone, P.; Vincenzi, B.; Citro, G.; Vicidomini, G.; Fasano, S.; Meccariello, R.; Cobellis, G.; et al. Global gene expression profiling of human pleural mesotheliomas: Identification of matrix metalloproteinase 14 (MMP-14) as potential tumour target. PLoS ONE 2009, 4, e7016. [CrossRef]

113. Suraokar, M.B.; Nunez, M.I.; Diao, L.; Chow, C.W.; Kim, D.; Behrens, C.; Lin, H.; Lee, S.; Raso, G.; Moran, C.; et al. Expression profiling stratifies mesothelioma tumors and signifies deregulation of spindle checkpoint pathway and microtubule network with therapeutic implications. Ann. Oncol. 2014, 25, 1184-1192. [CrossRef] [PubMed]

114. Kalluri, R.; Weinberg, R.A. The basics of epithelial-mesenchymal transition. J. Clin. Investing. 2009, 119, 1420-1428. [CrossRef] [PubMed]

115. Fassina, A.; Cappellesso, R.; Guzzardo, V.; Dalla Via, L.; Piccolo, S.; Ventura, L.; Fassan, M. Epithelial-mesenchymal transition in malignant mesothelioma. Mod. Pathol. 2012, 25, 86-99. [CrossRef] [PubMed]

116. Caldas, J.; Gehlenborg, N.; Kettunen, E.; Faisal, A.; Rönty, M.; Nicholson, A.G.; Knuutila, S.; Brazma, A.; Kaski, S. Data-driven information retrieval in heterogeneous collections of transcriptomics data links SIM2s to malignant pleural mesothelioma. Bioinformatics 2012, 28, 246-253. [CrossRef] [PubMed]

117. Alì, G.; Borrelli, N.; Riccardo, G.; Proietti, A.; Pelliccioni, S.; Niccoli, C.; Boldrini, L.; Lucchi, M.; Mussi, A.; Fontanini, G. Differential expression of extracellular matrix constituents and cell adhesion molecules between malignant pleural mesothelioma and mesothelial hyperplasia. J. Thorac. Oncol. 2013, 8, 1389-1395. [CrossRef] [PubMed]

118. Barone, E.; Gemignani, F.; Landi, S. Overexpressed genes in malignant pleural mesothelioma: Implications in clinical management. J. Thorac. Dis. 2018, 10, S369-S382. [CrossRef]

119. Turini, S.; Bergandi, L.; Gazzano, E.; Prato, M.; Aldieri, E. Epithelial to mesenchymal transition in human mesothelial cells exposed to asbestos fibers: Role of TGF- $\beta$ as mediator of malignant mesothelioma development or metastasis via EMT event. Int. J. Mol. Sci. 2019, 20, 150. [CrossRef]

120. Lo, S.K. Molecular Analyses of Malignant Pleural Mesothelioma. Ph.D. Thesis, Imperial College London, London, UK, 2016. [CrossRef]

121. Kim, M.-K.; Kim, H.; Jang, M.; Oh, S.S.; Yong, S.-J.; Jeong, Y.; Jung, S.-H.; Choi, J.-W. LOX family and ZFPM2 as novel diagnostic biomarkers for malignant pleural mesothelioma. Biomark. Res. 2020, 8, 1. [CrossRef]

122. Tamminen, J.A.; Parviainen, V.; Rönty, M.; Wohl, A.P.; Murray, L.; Joenväärä, S.; Varjosalo, M.; Leppäranta, O.; Ritvos, O.; Sengle, G.; et al. Gremlin-1 associates with fibrillin microfibrils in vivo and regulates mesothelioma cell survival through transcription factor slug. Oncogenesis 2013, 2, e66. [CrossRef]

123. Stockhammer, P.; Ploenes, T.; Theegarten, D.; Schuler, M.; Maier, S.; Aigner, C.; Hegedus, B. Detection of TGF- $\beta$ in pleural effusions for diagnosis and prognostic stratification of malignant pleural mesothelioma. Lung Cancer 2020, 139, 124-132. [CrossRef]

124. Rouka, E.; Vavougios, G.D.; Solenov, E.I.; Gourgoulianis, K.I.; Hatzoglou, C.; Zarogiannis, S.G. Transcriptomic analysis of the claudin interactome in malignant pleural mesothelioma: Evaluation of the effect of disease phenotype, asbestos exposure, and CDKN2A deletion status. Front. Physiol. 2017, 8. [CrossRef] [PubMed]

125. Christensen, B.C.; Houseman, E.A.; Godleski, J.J.; Marsit, C.J.; Longacker, J.L.; Roelofs, C.R.; Karagas, M.R.; Wrensch, M.R.; Yeh, R.-F.; Nelson, H.H.; et al. Epigenetic profiles distinguish pleural mesothelioma from normal pleura and predict lung asbestos burden and clinical outcome. Cancer Res. 2009, 69, 227-234. [CrossRef] [PubMed]

126. Christensen, B.C.; Houseman, E.A.; Poage, G.M.; Godleski, J.J.; Bueno, R.; Sugarbaker, D.J.; Wiencke, J.K.; Nelson, H.H.; Marsit, C.J.; Kelsey, K.T. Integrated profiling reveals a global correlation between epigenetic and genetic alterations in mesothelioma. Cancer Res. 2010, 70, 5686-5694. [CrossRef] [PubMed] 
127. Goto, Y.; Shinjo, K.; Kondo, Y.; Shen, L.; Toyota, M.; Suzuki, H.; Gao, W.; An, B.; Fujii, M.; Murakami, H.; et al. Epigenetic profiles distinguish malignant pleural mesothelioma from lung adenocarcinoma. Cancer Res. 2009, 69, 9073-9082. [CrossRef] [PubMed]

128. Cheng, Y.Y.; Mok, E.; Tan, S.; Leygo, C.; McLaughlin, C.; George, A.M.; Reid, G. SFRP tumour suppressor genes are potential plasma-based epigenetic biomarkers for malignant pleural mesothelioma. Dis. Mark. 2017, 2017, 2536187. [CrossRef] [PubMed]

129. McLoughlin, K.C.; Kaufman, A.S.; Schrump, D.S. Targeting the epigenome in malignant pleural mesothelioma. Transl. Lung Cancer Res. 2017, 6, 350-365. [CrossRef] [PubMed]

130. LaFave, L.M.; Béguelin, W.; Koche, R.; Teater, M.; Spitzer, B.; Chramiec, A.; Papalexi, E.; Keller, M.D.; Hricik, T.; Konstantinoff, K.; et al. Loss of BAP1 function leads to EZH2-dependent transformation. Nat. Med. 2015, 21, 1344-1349. [CrossRef]

131. Hoy, S.M. Tazemetostat: First approval. Drugs 2020, 80, 513-521. [CrossRef]

132. Chan, J.; Tay, Y. Noncoding RNA:RNA Regulatory Networks in Cancer. Int. J. Mol. Sci. 2018, 19, 1310. [CrossRef]

133. Djebali, S.; Davis, C.A.; Merkel, A.; Dobin, A.; Lassmann, T.; Mortazavi, A.; Tanzer, A.; Lagarde, J.; Lin, W.; Schlesinger, F.; et al. Landscape of transcription in human cells. Nature 2012, 489, 101-108. [CrossRef]

134. Geisler, S.; Coller, J. RNA in unexpected places: Long non-coding RNA functions in diverse cellular contexts. Nat. Rev. Mol. Cell Biol. 2013, 14, 699-712. [CrossRef] [PubMed]

135. Vidigal, J.A.; Ventura, A. The biological functions of miRNAs: Lessons from in vivo studies. Trends Cell Biol. 2015, 25, 137-147. [CrossRef] [PubMed]

136. Gutschner, T.; Diederichs, S. The hallmarks of cancer: A long non-coding RNA point of view. RNA Biol. 2012, 9, 703-719. [CrossRef] [PubMed]

137. Reddy, K.B. MicroRNA (miRNA) in cancer. Cancer Cell Int. 2015, 15, 38. [CrossRef]

138. Zhang, Y.-X.; Yuan, J.; Gao, Z.-M.; Zhang, Z.-G. LncRNA TUC338 promotes invasion of lung cancer by activating MAPK pathway. Eur. Rev. Med. Pharmacol. Sci. 2018, 22, 443-449. [CrossRef]

139. Martínez-Rivera, V.; Negrete-García, M.C.; Ávila-Moreno, F.; Ortiz-Quintero, B. Secreted and Tissue miRNAs as Diagnosis Biomarkers of Malignant Pleural Mesothelioma. Int. J. Mol. Sci. 2018, 19, 595. [CrossRef]

140. Mairinger, F.D.; Schmeller, J.; Borchert, S.; Wessolly, M.; Mairinger, E.; Kollmeier, J.; Hager, T.; Mairinger, T.; Christoph, D.C.; Walter, R.F.H.; et al. Immunohistochemically detectable metallothionein expression in malignant pleural mesotheliomas is strongly associated with early failure to platin-based chemotherapy. Oncotarget 2018, 9, 22254-22268. [CrossRef]

141. Reid, G.; Johnson, T.G.; van Zandwijk, N. Manipulating microRNAs for the treatment of malignant pleural mesothelioma: Past, present and future. Front. Oncol. 2020, 10, 105. [CrossRef]

142. Singh, A.; Heery, R.; Gray, S. In Silico and In Vitro analyses of lncrnas as potential regulators in the transition from the epithelioid to sarcomatoid histotype of malignant pleural mesothelioma (MPM). Int. J. Mol. Sci. 2018, 19, 1297. [CrossRef]

143. Kim, K.; Ko, Y.; Oh, H.; Ha, M.; Kang, J.; Kwon, E.J.; Kang, J.W.; Kim, Y.; Heo, H.J.; Kim, G.; et al. MicroRNA-98 is a prognostic factor for asbestos-induced mesothelioma. J. Toxicol. Environ. Health Part A 2020, 83, 126-134. [CrossRef]

144. Birnie, K.A.; Prêle, C.M.; Musk, A.W.B.; de Klerk, N.; Lee, Y.C.G.; Fitzgerald, D.; Allcock, R.J.N.; Thompson, P.J.; Creaney, J.; Badrian, B.; et al. MicroRNA signatures in malignant pleural mesothelioma effusions. Dis. Mark. 2019, 2019, 1-9. [CrossRef] [PubMed]

145. Matboli, M.; Shafei, A.E.; Azazy, A.E.; Reda, M.; El-Khazragy, N.; Nagy, A.A.; Ali, M.A.; Sobhi, M.; Abdel-Rahman, O. Clinical evaluation of circulating miR-548a-3p and -20a expression in malignant pleural mesothelioma patients. Biomark. Med. 2018, 12, 129-139. [CrossRef] [PubMed]

146. Schelch, K.; Kirschner, M.B.; Williams, M.; Cheng, Y.Y.; van Zandwijk, N.; Grusch, M.; Reid, G. A link between the fibroblast growth factor axis and the miR-16 family reveals potential new treatment combinations in mesothelioma. Mol. Oncol. 2018, 12, 58-73. [CrossRef] [PubMed]

147. Johnson, T.G.; Schelch, K.; Cheng, Y.Y.; Williams, M.; Sarun, K.H.; Kirschner, M.B.; Kao, S.; Linton, A.; Klebe, S.; McCaughan, B.C.; et al. Dysregulated expression of the MicroRNA miR-137 and its target YBX1 contribute to the invasive characteristics of malignant pleural mesothelioma. J. Thorac. Oncol. 2018, 13, 258-272. [CrossRef] [PubMed] 
148. Matboli, M.; Shafei, A.E.; Ali, M.A.; Gaber, A.I.; Galal, A.; Tarek, O.; Marei, M.; Khairy, E.; El-Khazragy, N.; Anber, N.; et al. Clinical significance of serum DRAM1 mRNA, ARSA mRNA, hsa-miR-2053 and IncRNA-RP1-86D1.3 axis expression in malignant pleural mesothelioma. J. Cell. Biochem. 2019, 120, 3203-3211. [CrossRef] [PubMed]

149. Higashiyama, S.; Iwabuki, H.; Morimoto, C.; Hieda, M.; Inoue, H.; Matsushita, N. Membrane-anchored growth factors, the epidermal growth factor family: Beyond receptor ligands. Cancer Sci. 2008, 99, 214-220. [CrossRef]

150. Lengyel, E.; Sawada, K.; Salgia, R. Tyrosine Kinase Mutations in Human Cancer. Capab. Matur. Model 2007, 7, 77-84. [CrossRef]

151. Jagadeeswaran, R.; Ma, P.C.; Seiwert, T.Y.; Jagadeeswaran, S.; Zumba, O.; Nallasura, V.; Ahmed, S.; Filiberti, R.; Paganuzzi, M.; Puntoni, R.; et al. Functional analysis of c-Met/hepatocyte growth factor pathway in malignant pleural mesothelioma. Cancer Res. 2006, 66, 352-361. [CrossRef]

152. Ohta, Y.; Shridhar, V.; Bright, R.K.; Kalemkerian, G.P.; Du, W.; Carbone, M.; Watanabe, Y.; Pass, H.I. VEGF and VEGF type $C$ play an important role in angiogenesis and lymphangiogenesis in human malignant mesothelioma tumours. Br. J. Cancer 1999, 81, 54-61. [CrossRef]

153. Ou, W.-B.; Corson, J.M.; Flynn, D.L.; Lu, W.-P.; Wise, S.C.; Bueno, R.; Sugarbaker, D.J.; Fletcher, J.A. AXL regulates mesothelioma proliferation and invasiveness. Oncogene 2011, 30, 1643-1652. [CrossRef]

154. Goparaju, C.; Donington, J.S.; Hsu, T.; Harrington, R.; Hirsch, N.; Pass, H.I. Overexpression of EPH receptor B2 in malignant mesothelioma correlates with oncogenic behavior. J. Thorac. Oncol. 2013, 8, 1203-1211. [CrossRef] [PubMed]

155. Wang, J.; Mirzapoiazova, T.; Carol Tan, Y.-H.; Pang, K.M.; Pozhitkov, A.; Wang, Y.; Wang, Y.; Mambetsariev, B.; Wang, E.; Nasser, M.W.; et al. Inhibiting crosstalk between MET signaling and mitochondrial dynamics and morphology: A novel therapeutic approach for lung cancer and mesothelioma. Cancer Biol. Therapy 2018, 19, 1023-1032. [CrossRef] [PubMed]

156. Massagué, J.; Blain, S.W.; Lo, R.S. TGF beta signaling in growth control, cancer, and heritable disorders. Cell 2000, 103, 295-309. [CrossRef]

157. Hoda, M.A.; Münzker, J.; Ghanim, B.; Schelch, K.; Klikovits, T.; Laszlo, V.; Sahin, E.; Bedeir, A.; Lackner, A.; Dome, B.; et al. Suppression of activin A signals inhibits growth of malignant pleural mesothelioma cells. Br. J. Cancer 2012, 107, 1978-1986. [CrossRef] [PubMed]

158. Tamminen, J.A.; Yin, M.; Rönty, M.; Sutinen, E.; Pasternack, A.; Ritvos, O.; Myllärniemi, M.; Koli, K. Overexpression of activin-A and -B in malignant mesothelioma-Attenuated Smad3 signaling responses and ERK activation promote cell migration and invasive growth. Exp. Cell Res. 2015, 332, 102-115. [CrossRef] [PubMed]

159. Komiya, E.; Ohnuma, K.; Yamazaki, H.; Hatano, R.; Iwata, S.; Okamoto, T.; Dang, N.H.; Yamada, T.; Morimoto, C. CD26-mediated regulation of periostin expression contributes to migration and invasion of malignant pleural mesothelioma cells. Biochem. Biophys. Res. Commun. 2014, 447, 609-615. [CrossRef]

160. Ishiguro, F.; Murakami, H.; Mizuno, T.; Fujii, M.; Kondo, Y.; Usami, N.; Yokoi, K.; Osada, H.; Sekido, Y. Activated leukocyte cell-adhesion molecule (ALCAM) Promotes malignant phenotypes of malignant mesothelioma. J. Thorac. Oncol. 2012, 7, 890-899. [CrossRef]

161. Takeuchi, S.; Fukuda, K.; Yamada, T.; Arai, S.; Takagi, S.; Ishii, G.; Ochiai, A.; Iwakiri, S.; Itoi, K.; Uehara, H.; et al. Podoplanin promotes progression of malignant pleural mesothelioma by regulating motility and focus formation. Cancer Sci. 2017, 108, 696-703. [CrossRef]

162. He, X.; Wang, L.; Riedel, H.; Wang, K.; Yang, Y.; Dinu, C.Z.; Rojanasakul, Y. Mesothelin promotes epithelial-to-mesenchymal transition and tumorigenicity of human lung cancer and mesothelioma cells. Mol. Cancer 2017, 16, 63. [CrossRef]

163. Servais, E.L.; Colovos, C.; Rodriguez, L.; Bograd, A.J.; Nitadori, J.-I.; Sima, C.; Rusch, V.W.; Sadelain, M.; Adusumilli, P.S. mesothelin overexpression promotes mesothelioma cell invasion and mmp-9 secretion in an orthotopic mouse model and in epithelioid pleural mesothelioma patients. Clin. Cancer Res. 2012, 18, 2478-2489. [CrossRef]

164. Zhang, W.-Q.; Dai, Y.-Y.; Hsu, P.-C.; Wang, H.; Cheng, L.; Yang, Y.-L.; Wang, Y.-C.; Xu, Z.-D.; Liu, S.; Chan, G.; et al. Targeting YAP in malignant pleural mesothelioma. J. Cell. Mol. Med. 2017, 21, 2663-2676. [CrossRef] [PubMed] 
165. Piccolo, S. Linking cancer transcriptional addictions by CDK7 to YAP/TAZ. Genes Dev. 2020, 34, 4-6. [CrossRef] [PubMed]

166. Miao, J.; Kyoyama, H.; Liu, L.; Chan, G.; Wang, Y.; Urisman, A.; Yang, Y.; Liu, S.; Xu, Z.; Bin, H.; et al. Inhibition of cyclin-dependent kinase 7 down-regulates yes-associated protein expression in mesothelioma cells. J. Cell. Mol. Med. 2020, 24, 1087-1098. [CrossRef] [PubMed]

167. Huang, J.; Tabata, S.; Kakiuchi, S.; The Van, T.; Goto, H.; Hanibuchi, M.; Nishioka, Y. Identification of pregnancy-associated plasma protein $\mathrm{A}$ as a migration-promoting gene in malignant pleural mesothelioma cells: A potential therapeutic target. Oncotarget 2013, 4, 1172-1184. [CrossRef]

168. Darnell, J.E. Transcription factors as targets for cancer therapy. Nat. Rev. Cancer 2002, 2, 740-749. [CrossRef]

169. Litwiniuk, M.M.; Rożnowski, K.; Filas, V.; Godlewski, D.D.; Stawicka, M.; Kaleta, R.; Bręborowicz, J. Expression of estrogen receptor beta in the breast carcinoma of BRCA1 mutation carriers. BMC Cancer 2008, 8, 100. [CrossRef]

170. Larsen, J.E.; Nathan, V.; Osborne, J.K.; Farrow, R.K.; Deb, D.; Sullivan, J.P.; Dospoy, P.D.; Augustyn, A.; Hight, S.K.; Sato, M.; et al. ZEB1 drives epithelial-to-mesenchymal transition in lung cancer. J. Clin. Investig. 2016, 126, 3219-3235. [CrossRef]

171. Shi, Q.; Le, X.; Abbruzzese, J.L.; Peng, Z.; Qian, C.N.; Tang, H.; Xiong, Q.; Wang, B.; Li, X.C.; Xie, K. Constitutive Sp1 activity is essential for differential constitutive expression of vascular endothelial growth factor in human pancreatic adenocarcinoma. Cancer Res. 2001, 61, 4143-4154.

172. Brett, A.; Pandey, S.; Fraizer, G. The Wilms' tumor gene (WT1) regulates E-cadherin expression and migration of prostate cancer cells. Mol. Cancer 2013, 12, 3. [CrossRef]

173. Merikallio, H.; Pääkkö, P.; Salmenkivi, K.; Kinnula, V.; Harju, T.; Soini, Y. Expression of snail, twist, and Zeb1 in malignant mesothelioma. APMIS 2013, 121,1-10. [CrossRef]

174. Rodríguez-Cid, J.R.; García-Acevedo, O.; Benjamin-Contreras, J.; Bonilla-Molina, D.; Flores-Mariñelarena, R.R.; Martínez-Barrera, L.; Alatorre-Alexander, J.A.; Sanchez-Ríos, C.P.; del Flores-Soto, M.R.; Santillan-Doherty, P.J.; et al. Expression of estrogen receptor beta (ER $\beta)$ and its prognostic value in pleural mesothelioma. J. Thorac. Dis. 2019, 11, 1456-1464. [CrossRef]

175. Rao, M.; Atay, S.M.; Shukla, V.; Hong, Y.; Upham, T.; Ripley, R.T.; Hong, J.A.; Zhang, M.; Reardon, E.; Fetsch, P.; et al. Mithramycin depletes specificity protein 1 and activates p53 to mediate senescence and apoptosis of malignant pleural mesothelioma cells. Clin. Cancer Res. 2016, 22, 1197-1210. [CrossRef] [PubMed]

176. Kushitani, K.; Takeshima, Y.; Amatya, V.J.; Furonaka, O.; Sakatani, A.; Inai, K. Immunohistochemical marker panels for distinguishing between epithelioid mesothelioma and lung adenocarcinoma. Pathol. Int. 2007, 57, 190-199. [CrossRef] [PubMed]

177. Horio, M.; Sato, M.; Takeyama, Y.; Elshazley, M.; Yamashita, R.; Hase, T.; Yoshida, K.; Usami, N.; Yokoi, K.; Sekido, Y.; et al. Transient but not stable ZEB1 knockdown dramatically inhibits growth of malignant pleural mesothelioma cells. Ann. Surg. Oncol. 2012, 19, 634-645. [CrossRef]

178. Pinton, G.; Thomas, W.; Bellini, P.; Manente, A.G.; Favoni, R.E.; Harvey, B.J.; Mutti, L.; Moro, L. Estrogen Receptor $\beta$ exerts tumor repressive functions in human malignant pleural mesothelioma via egfr inactivation and affects response to gefitinib. PLOS ONE 2010, 5, e14110. [CrossRef]

179. Plönes, T.; Fischer, M.; Höhne, K.; Sato, H.; Müller-Quernheim, J.; Zissel, G. Turning back the wheel: Inducing mesenchymal to epithelial transition via wilms tumor 1 knockdown in human mesothelioma cell lines to influence proliferation, invasiveness, and chemotaxis. Pathol. Oncol. Res. 2017, 23, 723-730. [CrossRef]

180. Abu Lila, A.S.; Kato, C.; Fukushima, M.; Huang, C.-L.; Wada, H.; Ishida, T. Downregulation of thymidylate synthase by RNAi molecules enhances the antitumor effect of pemetrexed in an orthotopic malignant mesothelioma xenograft mouse model. Int. J. Oncol. 2016, 48, 1399-1407. [CrossRef]

181. Monica, V.; Iacono, M.L.; Bracco, E.; Busso, S.; Blasio, L.D.; Primo, L.; Peracino, B.; Papotti, M.; Scagliotti, G. Dasatinib modulates sensitivity to pemetrexed in malignant pleural mesothelioma cell lines. Oncotarget 2016, 7, 76577-76589. [CrossRef]

182. Sudo, H.; Tsuji, A.B.; Sugyo, A.; Kohda, M.; Sogawa, C.; Yoshida, C.; Harada, Y.; Hino, O.; Saga, T. Knockdown of COPA, identified by loss-of-function screen, induces apoptosis and suppresses tumor growth in mesothelioma mouse model. Genomics 2010, 95, 210-216. [CrossRef] 
183. Roe, O.D.; Anderssen, E.; Sandeck, H.; Christensen, T.; Larsson, E.; Lundgren, S. Malignant pleural mesothelioma: Genome-wide expression patterns reflecting general resistance mechanisms and a proposal of novel targets. Lung Cancer 2010, 67, 57-68. [CrossRef]

184. Romagnoli, S.; Fasoli, E.; Vaira, V.; Falleni, M.; Pellegrini, C.; Catania, A.; Roncalli, M.; Marchetti, A.; Santambrogio, L.; Coggi, G.; et al. Identification of potential therapeutic targets in malignant mesothelioma using cell-cycle gene expression analysis. Am. J. Pathol. 2009, 174, 762-770. [CrossRef] [PubMed]

185. Linton, A.; Cheng, Y.Y.; Griggs, K.; Kirschner, M.B.; Gattani, S.; Srikaran, S.; Chuan-Hao Kao, S.; McCaughan, B.C.; Klebe, S.; van Zandwijk, N.; et al. An RNAi-based screen reveals PLK1, CDK1 and NDC80 as potential therapeutic targets in malignant pleural mesothelioma. Br. J. Cancer 2014, 110, 510-519. [CrossRef]

186. Xu, D.; Liang, S.-Q.; Yang, H.; Bruggmann, R.; Berezowska, S.; Yang, Z.; Marti, T.M.; Hall, S.R.R.; Gao, Y.; Kocher, G.J.; et al. CRISPR screening identifies WEE1 as a combination target for standard chemotherapy in malignant pleural mesothelioma. Mol. Cancer Ther. 2020, 19, 661-672. [CrossRef] [PubMed]

187. Okonska, A.; Bühler, S.; Rao, V.; Ronner, M.; Blijlevens, M.; van der Meulen-Muileman, I.H.; de Menezes, R.X.; Wipplinger, M.; Oehl, K.; Smit, E.F.; et al. Functional genomic screen in mesothelioma reveals that loss of function of BRCA1-Associated protein 1 induces chemoresistance to ribonucleotide reductase inhibition. Mol. Cancer Ther. 2020, 19, 552-563. [CrossRef] [PubMed]

188. DepMap: The Cancer Dependency Map Project at Broad Institute. Available online: https://depmap.org/ portal/ (accessed on 22 July 2020).

189. Tsherniak, A.; Vazquez, F.; Montgomery, P.G.; Weir, B.A.; Kryukov, G.; Cowley, G.S.; Gill, S.; Harrington, W.F.; Pantel, S.; Krill-Burger, J.M.; et al. Defining a cancer dependency map. Cell 2017, 170, 564-576. [CrossRef] [PubMed]

190. Broad DepMap 20Q1 Public 2020. Available online: https://depmap.org/portal/download (accessed on 8 May 2020).

191. McFarland, J.M.; Ho, Z.V.; Kugener, G.; Dempster, J.M.; Montgomery, P.G.; Bryan, J.G.; Krill-Burger, J.M.; Green, T.M.; Vazquez, F.; Boehm, J.S.; et al. Improved estimation of cancer dependencies from large-scale RNAi screens using model-based normalization and data integration. Nat. Commun. 2018, 9, 4610. [CrossRef]

192. Wang, T.; Birsoy, K.; Hughes, N.W.; Krupczak, K.M.; Post, Y.; Wei, J.J.; Lander, E.S.; Sabatini, D.M. Identification and characterization of essential genes in the human genome. Science 2015, 350, 1096-1101. [CrossRef]

193. Tang, Z.; Li, C.; Kang, B.; Gao, G.; Li, C.; Zhang, Z. GEPIA: A web server for cancer and normal gene expression profiling and interactive analyses. Nucl. Acids Res. 2017, 45, W98-W102. [CrossRef]

194. Chandrashekar, D.S.; Bashel, B.; Balasubramanya, S.A.H.; Creighton, C.J.; Ponce-Rodriguez, I.; Chakravarthi, B.V.S.K.; Varambally, S. UALCAN: A Portal for facilitating tumor subgroup gene expression and survival analyses. Neoplasia 2017, 19, 649-658. [CrossRef]

195. Dell'Anno, I.; Barbarino, M.; Barone, E.; Giordano, A.; Luzzi, L.; Bottaro, M.; Migliore, L.; Agostini, S.; Melani, A.; Melaiu, O.; et al. EIF4G1 and RAN as Possible Drivers for Malignant Pleural Mesothelioma. Int. J. Mol. Sci. 2020, 21, 4856. [CrossRef]

196. Quispel-Janssen, J.M.; Badhai, J.; Schunselaar, L.; Price, S.; Brammeld, J.; Iorio, F.; Kolluri, K.; Garnett, M.; Berns, A.; Baas, P.; et al. Comprehensive pharmacogenomic profiling of malignant pleural mesothelioma identifies a subgroup sensitive to FGFR inhibition. Clin. Cancer Res. 2018, 24, 84-94. [CrossRef] [PubMed]

197. Schunselaar, L.M.; Quispel-Janssen, J.M.M.F.; Kim, Y.; Alifrangis, C.; Zwart, W.; Baas, P.; Neefjes, J. Chemical profiling of primary mesothelioma cultures defines subtypes with different expression profiles and clinical responses. Clin. Cancer Res. 2018, 24, 1761-1770. [CrossRef] [PubMed]

198. Mazzocchi, A.R.; Rajan, S.A.P.; Votanopoulos, K.I.; Hall, A.R.; Skardal, A. In vitro patient-derived 3D mesothelioma tumor organoids facilitate patient-centric therapeutic screening. Sci. Rep. 2018, 8, 2886. [CrossRef] [PubMed]

199. Wu, L.; Allo, G.; John, T.; Li, M.; Tagawa, T.; Opitz, I.; Anraku, M.; Yun, Z.; Pintilie, M.; Pitcher, B.; et al. Patient-derived xenograft establishment from human malignant pleural mesothelioma. Clin. Cancer Res. 2017, 23, 1060-1067. [CrossRef] [PubMed]

200. Altomare, D.A.; Vaslet, C.A.; Skele, K.L.; De Rienzo, A.; Devarajan, K.; Jhanwar, S.C.; McClatchey, A.I.; Kane, A.B.; Testa, J.R. A Mouse model recapitulating molecular features of human mesothelioma. Cancer Res. 2005, 65, 8090-8095. [CrossRef] 
201. Jongsma, J.; van Montfort, E.; Vooijs, M.; Zevenhoven, J.; Krimpenfort, P.; van der Valk, M.; van de Vijver, M.; Berns, A. A Conditional mouse model for malignant mesothelioma. Cancer Cell 2008, 13, 261-271. [CrossRef]

202. Sementino, E.; Menges, C.W.; Kadariya, Y.; Peri, S.; Xu, J.; Liu, Z.; Wilkes, R.G.; Cai, K.Q.; Rauscher, F.J.; Klein-Szanto, A.J.; et al. Inactivation of Tp53 and Pten drives rapid development of pleural and peritoneal malignant mesotheliomas. J. Cell. Phys. 2018, 233, 8952-8961. [CrossRef]

203. Badhai, J.; Pandey, G.K.; Song, J.-Y.; Krijgsman, O.; Bhaskaran, R.; Chandrasekaran, G.; Kwon, M.-C.; Bombardelli, L.; Monkhorst, K.; Grasso, C.; et al. Combined deletion of Bap1, Nf2, and Cdkn2ab causes rapid onset of malignant mesothelioma in mice. J. Exp. Med. 2020, 217. [CrossRef]

204. Kukuyan, A.-M.; Sementino, E.; Kadariya, Y.; Menges, C.W.; Cheung, M.; Tan, Y.; Cai, K.Q.; Slifker, M.J.; Peri, S.; Klein-Szanto, A.J.; et al. Inactivation of Bap1 cooperates with losses of Nf2 and Cdkn2a to drive the development of pleural malignant mesothelioma in conditional mouse models. Cancer Res. 2019, 79, 4113-4123. [CrossRef]

205. Xu, J.; Kadariya, Y.; Cheung, M.; Pei, J.; Talarchek, J.; Sementino, E.; Tan, Y.; Menges, C.W.; Cai, K.Q.; Litwin, S.; et al. Germline mutation of Bap1 accelerates development of asbestos-induced malignant mesothelioma. Cancer Res. 2014, 74, 4388-4397. [CrossRef]

206. Napolitano, A.; Pellegrini, L.; Dey, A.; Larson, D.; Tanji, M.; Flores, E.G.; Kendrick, B.; Lapid, D.; Powers, A.; Kanodia, S.; et al. Minimal asbestos exposure in germline BAP1 heterozygous mice is associated with deregulated inflammatory response and increased risk of mesothelioma. Oncogene 2016, 35, 1996-2002. [CrossRef] [PubMed]

207. Kadariya, Y.; Cheung, M.; Xu, J.; Pei, J.; Sementino, E.; Menges, C.W.; Cai, K.Q.; Rauscher, F.J.; Klein-Szanto, A.J.; Testa, J.R. Bap1 is a bona fide tumor suppressor: Genetic evidence from mouse models carrying heterozygous germline Bap1 mutations. Cancer Res. 2016, 76, 2836-2844. [CrossRef] [PubMed]

(C) 2020 by the authors. Licensee MDPI, Basel, Switzerland. This article is an open access article distributed under the terms and conditions of the Creative Commons Attribution (CC BY) license (http://creativecommons.org/licenses/by/4.0/). 